Fire-Plume-Generated Ceiling Jet Characteristics and Convective Heat Transfer to Ceiling and Wall Surfaces in a Two-Layer Zone-Type Fire Environment: Uniform Temperature Ceiling and Walls 



\section{Fire-Plume-Generated Ceiling Jet Characteristics and Convective Heat Transfer to Ceiling and Wall Surfaces in a Two-Layer Zone-Type Fire Environment: Uniform Temperature Ceiling and Walls}

Leonard Y. Cooper

November 1991

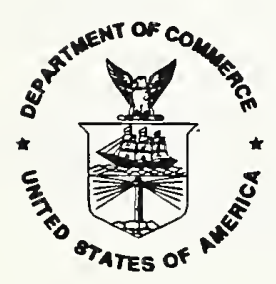

U.S. Department of Commerce Robert A. Mosbacher, Secretary National Institute of Standards and Technology John W. Lyons, Director Building and Fire Research Laboratory Gaithersburg, MD 20899

Sponsored by:

U.S. Nuclear Regulatory Commission Washington, DC 20555 



\section{TABLE OF CONTENTS}

$\underline{\text { Iuge }}$

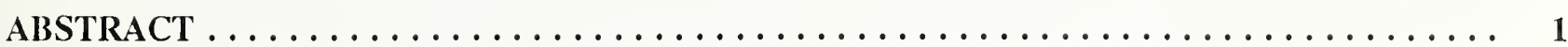

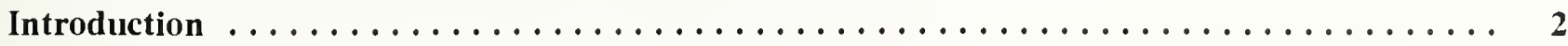

Room Geometry, Characterization of the Instantaneous State of the Fire, the Fire Plume, and

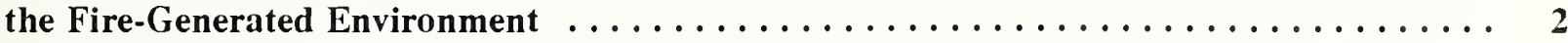

Overview of Plume/Upper-Layer Interaction and Ceiling Heat Transfer $\ldots \ldots \ldots \ldots \ldots$

Properties of the Plume in the Upper Layer When $\mathrm{Z}_{\mathrm{FIRE}}<\mathrm{Z}_{\mathrm{LAYER}} \ldots \ldots \ldots \ldots \ldots$

General Properties of the Plume in the Upper Layer and/or Near the Ceiling $\ldots \ldots \ldots \ldots$

Calculating the Convective Heat Transfer to the Ceiling $\ldots \ldots \ldots \ldots \ldots \ldots \ldots$

Calculating the Average Convective Heat Transfer to the Upper and Lower Wall Surfaces ... 8 Locations of Normal Ceiling-Jet/Wall Impingement . . . . . . . . . . . . . . 8

Strategy for Estimating Heat Transfer to the Walls . . . . . . . . . . . . . . . . . . 9

The Computer Subroutine CEILHT for Carrying out the Heat Transfer Calculations $\ldots \ldots \ldots 10$

Velocity and Temperature Distributions in the Ceiling Jet $\ldots \ldots \ldots \ldots \ldots \ldots \ldots \ldots$

The Velocity Distribution . . . . . . . . . . . . . . . . . . . . . . . 11

The Temperature Distribution ............................ 12

Summary $\ldots \ldots \ldots \ldots \ldots \ldots \ldots \ldots \ldots \ldots \ldots \ldots \ldots \ldots \ldots \ldots \ldots \ldots \ldots \ldots \ldots \ldots \ldots$

Acknowledgements $\ldots \ldots \ldots \ldots \ldots \ldots \ldots \ldots \ldots \ldots \ldots \ldots \ldots \ldots \ldots \ldots \ldots \ldots \ldots \ldots$

Nomenclature $\ldots \ldots \ldots \ldots \ldots \ldots \ldots \ldots \ldots \ldots \ldots \ldots \ldots \ldots \ldots \ldots \ldots \ldots \ldots \ldots$

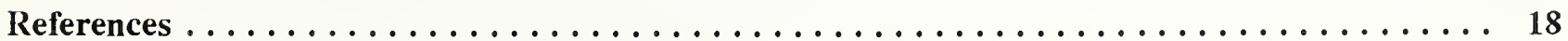

Appendix A: An Algorithm for Estimating the Average Rate of Ceiling-Jet-Driven Convective Heat Transfer to the Upper and Lower Layer Walls . . . . . . . . . . . . . . 20

Appendix B: The Subroutine CEILHT for Calculating the Convective Heat Transfer in a Two-Layer Fire Environment From Fire Plume Gases to a Uniform Temperature Ceiling and to Uniform Temperature Walls. . . . . . . . . . 23 


\section{LIST OF FIGURES}

Figure 1. Fire in a rectangular parallelopiped enclosure. $\ldots \ldots \ldots \ldots \ldots \ldots \ldots \ldots$

Figure 2. The fire and the equivalent source in the lower layer and the continuation source in the extended upper layer. . . . . . . . . . . . . . . . . . . 48

Figure 3. Overview of the CEILHT Algorithm. . . . . . . . . . . . . . . . . . 49

Figure 4. A plot of dimensionless ceiling jet velocity distribution, $\mathrm{V}_{\mathrm{CJ}} / \mathrm{V}_{\mathrm{MAX}}$, as a function of $\mathrm{z} /(0.23 \delta)$ per Eq. (29). ........................... 50

Figure 5. Plots of dimensionless ceiling jet temperature distribution, $\Theta$, as a function of $\mathrm{z} /(0.23 \delta)$ per Eq. (32) for cases when $\Theta_{\mathrm{S}}$ is $<0$, between 0 and 1 , and $>0 . \ldots \ldots 5$

Figure 6. Definition of the Wall Stagnation Points, Room Corners, and Wall Segments. . . . 52 


\title{
FIRE-PLUME-GENERATED CEILING JET CHARACTERISTICS AND CONVECTIVE HEAT TRANSFER TO CEILING AND WALL SURFACES IN A TWO-LAYER ZONE- TYPE FIRE ENVIRONMENT: UNIFORM TEMPERATURE CEILING AND WALLS
}

\author{
Leonard Y. Cooper
}

\begin{abstract}
It has been determined by Sandia National Laboratories and the US Nuclear Regulatory Commission that the use of deterministic, multi-room, zone-type fire modeling technology could enhance the reliability of their recent reactor safety risk studies. These studies are confined to the relatively early detection times of fire development when fire-driven ceiling jets and gas-to-ceiling convective heat transfer are expected to play a particularly important role in room-to-room smoke spread and in the response of near-ceiling mounted detection hardware. A parameter of concern in these risk analyses is the location of the fire within the space of fire origin. One goal of the analyses is to determine the significance to risk of this fire-position parameter.
\end{abstract}

This work presents a model to predict the instantaneous rate of convective heat transfer from fire plume gases to the overhead ceiling surface in a room of fire origin. The room is assumed to be a rectangular parallelopiped and, at times of interest, ceiling temperatures are simulated as being uniform. Also presented is an estimate of the convective heat transfer, due to ceiling-jet-driven wall flows, to both the upper and lower portions of the walls. The effect on the heat transfer of the location of the fire within the room is taken into account. Finally presented is a model of the velocity and temperature distributions in the ceiling jet.

The model equations were used to develop an algorithm and associated modular computer subroutine to carry out the indicated heat transfer calculations. The subroutine is written in FORTRAN 77 and called CEILHT. The algorithm and subroutine are suitable for use in two-layer zone-type compartment fire model computer codes. The subroutine was tested for a variety of fire environments involving a $10^{7} \mathrm{~W}$ fire in a $8 \mathrm{~m} \mathrm{x} 8 \mathrm{~m} \times 4 \mathrm{~m}$ high enclosure. While the calculated results were plausible, it is important to point out that CEILHT simulations have not been experimentally validated.

Keywords: building fires; ceiling jets; compartment fires; computer models; fire models; heat transfer; mathematical models; zone models 


\section{Introduction}

It has been determined by Sandia National Laboratories and the US Nuclear Regulatory Commission that the use of deterministic, multi-room, zone-type fire modeling technology could enhance the reliability of their recent reactor safety risk studies. These studies are confined to the relatively early detection times of fire development when fire-driven ceiling jets and gas-to-ceiling convective heat transfer are expected to play a particularly important role in room-to-room smoke spread and in the response of near-ceiling mounted detection hardware. A parameter of concern in these risk analyses is the location of the fire within the space of fire origin. One goal of the analyses is to determine the significance to risk of this fire-position parameter. The purpose of this work is to develop and present a means of simulating the heat transfer and flow phenomena so that they can be included in two-layer zone-type fire model computer codes.

Consider a room of fire origin in a multi-room facility. At some arbitrary instant during a dynamic fire scenario assume that the fire-generated environment in the room can be reasonably simulated by upper and lower uniform-property layers where the two layers are stably-stratified (i.e., the upper layer temperature is greater than the lower layer temperature).

Consistent with several two-layer zone-type compartment fire model computer codes (see e.g., References [1], [2], and [3]) assume that it is reasonable to simulate the room's ceiling temperature as uniform. One objective of this work is to develop an algorithm and associated computer subroutine, useable in such fire models, to predict the instantaneous rate of convective heat transfer from the fire plume to the ceiling surface. In developing the heat transfer simulation it is desired to account for the location of the fire within the room. Estimates of the rates of convective heat transfer to the upper-layer portion of the wall surfaces (i.e., the portion submerged by the upper layer) and lower-layer portion of the wall surfaces will also be provided. A second objective of this work is to provide an estimate of the velocity and temperature distributions in the ceiling jet which is formed by plume/ceiling impingement and radial spread of the plume gases.

Let the room be a rectangular parallelopiped where the geometry is specified and, at a time of interest, assume that the fire environment in the room and the characteristics of the fire itself have been determined.

\section{Room Geometry, Characterization of the Instantaneous State of the Fire, the Fire Plume, and the Fire-Generated Environment}

Define a right-handed cartesian coordinate system with axes $X, Y, Z$ and with origin at a lower corner of the room, i.e., at the floor elevation. Orient the axes so that the $\mathrm{Z}$ axis is directed upward and the $\mathrm{X}$ and $\mathrm{Y}$ axes are aligned along the junction of the walls and the floor. Designate the coordinates of corner of the room furthest from the origin of the axes as $X_{\text {WALL }}, Y_{W A L L}$, and $Z_{\text {CEIL }}$. These are the length, width, and ceiling height of the room, respectively. Designate the co-ordinates of the center of the base of the fire as $\mathrm{X}_{\mathrm{FIRE}}, \mathrm{X}_{\mathrm{FIRE}}$, and $\mathrm{Z}_{\mathrm{FIRE}}$.

Characterize and specify the state of the fire-generated environment in the room by: the average densities and assumed uniform temperatures of the upper and lower gas layers, $\rho_{U}, T_{U}$, and $\rho_{L}, T_{L}$, respectively; the temperature of the ceiling surface and the average temperature of the wall surfaces, 
$\mathrm{T}_{\mathrm{CEIL}}$ and $\mathrm{T}_{\mathrm{WALL}}$, respectively; and the elevation above the floor of the interface between the two gas layers, $\mathrm{Z}_{\mathrm{LAYER}}$. A plan view and an elevation view of the geometry is depicted in Figure 1.

Define and specify $\dot{\mathrm{Q}}_{\mathrm{FCONV}}$ as the portion of the total fire energy release rate convected in the fire plume (i.e., the total rate of combustion energy release less the rate of energy radiated from the combustion zone and the plume). If the fire is below the layer interface, $Z_{\text {FIRE }}<Z_{\text {LAYER }}$, then characterize the mass flow rate and the convected enthalpy flow rate in the plume at $Z_{\text {LAYER }}$ as $\dot{\mathrm{M}}_{\text {PLUME }}$ and $\dot{\mathrm{Q}}_{\text {PLUME }}$, respectively.

Let $\dot{\mathrm{M}}_{\text {PLUME }}$ be specified. Then, assuming that the fuel flow rate is negligible compared to $\dot{\mathrm{M}}_{\text {PLUME}}$,

$$
\dot{\mathrm{Q}}_{\mathrm{PLUME}}=\dot{\mathrm{M}}_{\mathrm{PLUME}} \mathrm{C}_{\mathrm{p}} \mathrm{T}_{\mathrm{L}}+\dot{\mathrm{Q}}_{\mathrm{FCONV}}
$$

\section{Overview of Plume/Upper-Layer Interaction and Ceiling Heat Transfer}

The buoyant fire plume rises from $Z_{\text {FIRE }}$ toward the ceiling. When the fire is below the layer interface, its mass and enthalpy flow, $\mathrm{M}_{\mathrm{PLUME}}$ and $\mathrm{Q}_{\mathrm{PLUME}}$, are assumed to be deposited into the upper layer at $Z_{\text {LAYER }}$. Having penetrated the interface, a portion of the plume typically continues to rise toward the ceiling. As it impinges on the ceiling surface, the plume gases turn and form a relatively high temperature, high velocity, turbulent ceiling jet which flows radially outward along the ceiling and transfers heat to the relatively cool ceiling surface. The ceiling jet is cooled by convection and the ceiling material is heated indepth by conduction. The convective heat transfer rate is a strong function of the radial distance from the point of plume/ceiling impingement, reducing rapidly with increasing radius. It is dependent also on the characteristics of the plume immediately upstream of ceiling impingement.

The relatively high temperature ceiling jet is blocked eventually by the relatively cool wall surfaces. IN THIS WORK IT IS ASSUMED THAT THE DISTANCE BETWEEN THE PLUME/CEILING IMPINGEMENT POINT AND THE CLOSEST WALL SURFACE IS NEVER LESS THAN $0.2\left(\mathrm{Z}_{\text {CEIL }}\right.$ - $Z_{\text {FIRE}}$ ). Ceiling-jet/wall-surface impingement leads to stagnation-point-type enhancement of jet-tosurface heat transfer [4]. The ceiling jet then turns downward and outward in a complicated flow along the vertical wall surfaces (see [5] and [6]). Convective wall-flow-to-wall-surface heat transfer continues. The descent of the wall flows and the heat transfer from them are stopped eventually by upward buoyant forces. They are then buoyed back upward and mix finally with the upper layer.

Let $\dot{\mathrm{q}}_{\mathrm{CEIL}}^{\prime}(\mathrm{X}, \mathrm{Y})$ be the instantaneous flux of convective heat transfer from the ceiling jet gases to the ceiling surface and let $\dot{q}_{\mathrm{CEIL,AVE}}^{\prime}$ and $\dot{\mathrm{Q}}_{\mathrm{CEIL}}$ be its average value and the value of its integral, respectively, over the entire ceiling surface. The first objective of this work is to determine

$$
\dot{\mathrm{Q}}_{\mathrm{CEIL}}=\left(\mathrm{X}_{\mathrm{WALL}} \mathrm{Y}_{\mathrm{WALL}}\right) \dot{\mathrm{q}}_{\mathrm{CEIL,AVE}}^{\prime \prime}=\int_{0}^{\mathrm{X}_{\mathrm{WALL}}} \int_{0}^{Y_{\mathrm{WALL}}} \dot{\mathrm{q}}_{\mathrm{CEIL}}^{\mathrm{n}}(\mathrm{X}, \mathrm{Y}) \mathrm{dXdY}
$$




\section{Properties of the Plume in the Upper Layer When $\mathrm{Z}_{\mathrm{FIRE}}<\mathrm{Z}_{\mathrm{LAYER}}$}

Consider times when the elevation of the fire is below the interface, i.e., when $Z_{\text {FIRE }}<Z_{\text {LAYER }}$.

As the plume flow enters the upper layer the forces of buoyancy which drove the plume toward the layer interface (i.e., as a result of relatively high-temperature, low-density plume gases being submerged in a relatively cool, high-density lower-layer environment) are reduced immediately because of the increase of temperature of the upper layer environment over that of the lower layer. The continued ascent of the plume gases will be less vigorous, i.e., at reduced velocity, and of higher temperature than it would have been in the absence of the layer. Indeed, some of the penetrating plume flow, will actually be at a lower temperature than $T_{U}$. The upper layer buoyant forces on this latter portion of the flow will actually retard and possibly stop its subsequent rise to the ceiling.

The simple point-source Gaussian-distribution plume model of [7] will be used to simulate the plume flow, first immediately below, or upstream of the interface, and then throughout the depth of the upper layer itself.

Consider a Reference-[7]-type point source of buoyancy, with elevation below $\mathrm{Z}_{\mathrm{LAYER}}$. Then the plume above such a source will be taken to be equivalent to the plume of our fire (in the sense of having identical mass and enthalpy flow rates at the interface) if the point source strength is $\dot{\mathrm{Q}}_{\mathrm{FCONV}}$ and the elevation of the equivalent source, $\mathrm{Z}_{\mathrm{EQ}}$, satisfies

$$
\dot{\mathrm{M}}_{\mathrm{PLUME}}=0.21 \rho_{\mathrm{L}} \mathrm{g}^{1 / 2}\left(\mathrm{Z}_{\mathrm{LAYER}}-\mathrm{Z}_{\mathrm{EQ}}\right)^{5 / 2} \dot{\mathrm{Q}}_{\mathrm{EQ}}^{*} 1 / 3
$$

where $\dot{\mathrm{Q}}_{\mathrm{EQ}}^{*}$, a dimensionless measure of the strength of the fire plume at $\mathrm{Z}_{\mathrm{LAYER}}$, is defined by

$$
\dot{\mathrm{Q}}_{\mathrm{EQ}}^{*}=\dot{\mathrm{Q}}_{\mathrm{FCONV}} /\left[\rho_{\mathrm{L}} \mathrm{C}_{\mathrm{p}} \mathrm{T}_{\mathrm{L}} \mathrm{g}^{1 / 2}\left(\mathrm{Z}_{\mathrm{LAYER}}-\mathrm{Z}_{\mathrm{EQ}}\right)^{5 / 2}\right]
$$

and where $C_{p}$ is the specific heat at constant pressure of the entrained gas, which can be assumed to be identical to that of air.

Solving (3) and (4) for $\mathrm{Z}_{\mathrm{EQ}}$ and $\dot{\mathrm{Q}}_{\mathrm{EQ}}^{*}$ in terms of known variables leads to

$$
\begin{aligned}
& \dot{\mathrm{Q}}_{\mathrm{EQ}}^{*}=\left[0.21 \dot{\mathrm{Q}}_{\mathrm{FCONV}} /\left(\mathrm{C}_{\mathrm{p}} \mathrm{T}_{\mathrm{L}} \dot{\mathrm{M}}_{\mathrm{PLUME}}\right)\right]^{3 / 2} \\
& \mathrm{Z}_{\mathrm{EQ}}=\mathrm{Z}_{\mathrm{LAYER}}-\left[\dot{\mathrm{Q}}_{\mathrm{FCONV}} /\left(\dot{\mathrm{Q}}_{\mathrm{EQ}}^{*} \rho_{\mathrm{L}} \mathrm{C}_{\mathrm{p}} \mathrm{T}_{\mathrm{L}} \mathrm{g}^{1 / 2}\right)\right]^{2 / 5}
\end{aligned}
$$

As the plume crosses the interface, the fraction, $\dot{M}^{*}$, of $\dot{M}_{\text {PLUME }}$ which is still buoyant relative to the upper layer environment and presumably continues to rise to the ceiling, entraining upper layer gases along the way, is predicted in [8] to be 


$$
\dot{\mathrm{M}}^{*}= \begin{cases}0 & \text { if }-1<\sigma \leq 0 \\ \left(1.04599 \sigma+0.360391 \sigma^{2}\right) /\left(1 .+1.37748 \sigma+0.360391 \sigma^{2}\right) & \text { if } \sigma>0\end{cases}
$$

where the dimensionless parameter $\sigma$ is defined as

$$
\begin{aligned}
& \sigma=\left(1-\alpha+\mathrm{C}_{\mathrm{T}} \dot{\mathrm{Q}}_{\mathrm{EQ}}^{*}{ }^{2 / 3}\right) /(\alpha-1) \\
& \alpha=\mathrm{T}_{\mathrm{U}} / \mathrm{T}_{\mathrm{L}} ; \mathrm{C}_{\mathrm{T}}=9.115
\end{aligned}
$$

If $\dot{M}^{*}>0$, Reference [8] further identifies the parameters necessary to describe plume flow continuation in the upper layer (i.e., between $Z_{\text {LAYER }}$ and $Z_{\text {CEIL }}$ ) according to a Reference-[7]-type point source plume. It has been determined there that this plume can be modeled as being driven by a non-radiating continuation buoyant point source of strength Q' located a distance

$$
\mathrm{H}=\mathrm{Z}_{\mathrm{CEIL}}-\mathrm{Z}_{\text {SOURCE }}^{\prime}>\mathrm{Z}_{\mathrm{CEIL}}-\mathrm{Z}_{\mathrm{FIRE}}
$$

below the ceiling in a (downward-) extended upper layer environment of temperature $T_{U}$ and density $\rho_{\mathrm{U}}$. The relevant parameters predicted in [8] are

$$
\begin{aligned}
& \dot{\mathrm{Q}}^{\prime}=\dot{\mathrm{Q}}_{\mathrm{FCONV}} \sigma \dot{\mathrm{M}}^{*} /(1+\sigma) \\
& \mathrm{Z}_{\mathrm{SOURCE}}^{\prime}=\mathrm{Z}_{\mathrm{LAYER}}-\left(\mathrm{Z}_{\mathrm{LAYER}}-\mathrm{Z}_{\mathrm{EQ}}\right) \alpha^{3 / 5} \dot{\mathrm{M}}^{* 2 / 5}[(1+\sigma) / \sigma]^{1 / 5}
\end{aligned}
$$

The fire and the equivalent source in the lower layer and the continuation source in the upper layer are depicted in Figure 2. Times during a fire simulation when Eq. (8) predicts $\sigma>1$ are related to states of the fire environment when the temperatures above $\mathrm{T}_{\mathrm{L}}$ of the radial Gaussian temperature distribution of the plume flow, at the elevation of interface penetration, is predicted to be mostly much larger than $\left(T_{U}-T_{L}\right)$. Under such circumstances the penetrating plume flow is still very strongly buoyant as it enters the upper layer. The plume will continue to rise to the ceiling and to drive ceiling jet convective heat transfer at rates which differ only slightly (on account of the elevated temperature upper layer environment) from the heat transfer rates which could occur in the absence of an upper layer.

Conditions where Eq. (8) predicts $\sigma<0$ are related to times during a fire scenario when the temperature of the plume at the elevation of interface penetration is predicted to be uniformly less than $\mathrm{T}_{\mathrm{U}}$. Under such circumstances the penetrating plume flow is nowhere positively (i.e., upward) 
buoyant as it enters the upper layer. Thus, while all of this flow is assumed to enter and mix with the upper layer, it is assumed further that none of it rises to the ceiling in a coherent plume, i.e., Q' $=0$. For this reason, when $\sigma<0$ the model precludes to existence of any significant ceiling jet flow and associated convective heat transfer to the ceiling surface.

The above analysis assumes that $Z_{\text {FIRE }}<Z_{\text {LAYER }}$. However, at the onset of a fire scenario it is typical that $\mathrm{Z}_{\text {FIRE }}<\mathrm{Z}_{\text {LAYER }}=\mathrm{Z}_{\text {CEIL }}$ and $\alpha, \sigma$ and $\dot{\mathrm{M}}^{*}$ of Eqs. (7)-(9), which depend on the indeterminate initial value of $\mathrm{T}_{U}$, are themselves undefined. The situation when $\mathrm{Z}_{\mathrm{LAYER}}=\mathrm{Z}_{\mathrm{CEIL}}$ is properly taken into account if $\dot{Q}^{\prime}=\dot{Q}_{\text {FCONV }}$ and $Z_{\text {SOURCE }}^{\prime}=Z_{E Q}$.

\section{General Properties of the Plume in the Upper Layer and/or Near the Ceiling}

When $Z_{\text {FIRE }}<Z_{\text {LAYER }}<Z_{\text {CEIL }}$, the results of Eqs. (11) and (12) allow a description of the firedriven plume dynamics in the upper layer, up to plume/ceiling impingement at $Z_{\text {LAYER }}$, i.e., by using the continuation point source and the plume model of [7] in the extended upper layer. When $\mathrm{Z}_{\text {LAYER }}<\mathrm{Z}_{\text {FIRE }}$, the same plume model is used, but $\dot{Q}^{\prime}$ and $\mathrm{Z}_{\text {SOURCE }}^{\prime}$ are taken to be the convected buoyant strength of the fire and the actual fire elevation, respectively. Finally, when $\mathrm{Z}_{\text {LAYER }}=$ $\mathrm{Z}_{\mathrm{CEIL}}$, the plume dynamics near the ceiling is described by the equivalent point source, which is in the lower layer, and the point source plume model.

All cases can be treated with the following final versions of Eqs. (11) and (12)

$$
\begin{aligned}
& \dot{Q}^{\prime}= \begin{cases}\dot{Q}_{\text {FCONV }} \sigma \dot{M}^{*} /(1+\sigma) & \text { if } Z_{\text {FIRE }}<Z_{\text {LAYER }}<Z_{\text {CEIL }} \\
\dot{Q}_{\text {FCONV }} & \text { if } Z_{\text {FIRE }} \geq Z_{\text {LAYER }} \text { or if } Z_{\text {LAYER }}=Z_{\text {CEIL }}\end{cases} \\
& Z_{\text {SOURCE }}^{\prime}= \begin{cases}Z_{\text {EQ }} & \text { if } Z_{\text {LAYER }}=Z_{\text {CEIL }} ; \\
Z_{\text {LAYER }}-\left(Z_{\text {LAYER }}-Z_{\text {EQ }}\right) \alpha^{3 / 5} \dot{M}^{* 2 / 5}[(1+\sigma) / \sigma]^{1 / 5} \\
Z_{\text {FIRE }} & \text { if } Z_{\text {FIRE }}<Z_{\text {LAYER }}<Z_{\text {CEIL }} \\
\text { if } Z_{\text {LAYER }} \leq Z_{\text {FIRE }}<Z_{C E I L}\end{cases}
\end{aligned}
$$

where $\mathrm{Z}_{\mathrm{EQ}}, \dot{\mathrm{M}}^{*}, \sigma$, and $\alpha$ are calculated from Eqs. (5)-(9).

\section{Calculating the Convective Heat Transfer to the Ceiling}

When the fire is below the interface and the interface is below the ceiling the method of [9] will be used to calculate $\dot{q}_{C E I L}$. The method of [9] was developed to treat generic, confined-ceiling, room fire scenarios. The confined ceiling problem is solved by applying the unconfined ceiling heat transfer 
solution to the problem of an Eq. (11')-(12') equivalent upper layer source in an extended upper layer environment $[10,11]$. When the fire is above the interface, the unconfined ceiling methodology applies directly. This solution technique has been used previously in [12] and [13].

The equivalent, extended-upper-layer, unconfined-ceiling flow and heat transfer problem is depicted in the right-hand sketch of Figure 2. It involves the equivalent Q' heat source of Eq. (11') located a distance $\mathrm{H}$ below the ceiling surface in an extended lower layer environment where $\mathrm{H}$ is found from Eqs. (10) and (12'). The objective here is to estimate the $\dot{\mathrm{q}}_{\mathrm{CEIL}}^{\prime \prime}(\mathrm{X}, \mathrm{Y})$ distribution for the scenario in the latter sketch, and then its Eq. (2) integral over the ceiling surface.

From [10] and [11]

$$
\dot{\mathrm{q}}_{\mathrm{CEIL}}^{\prime \prime}(\mathrm{X}, \mathrm{Y})=\mathrm{h}_{\mathrm{L}}\left(\mathrm{T}_{\mathrm{AD}}-\mathrm{T}_{\mathrm{CEIL}}\right)
$$

where $\mathrm{T}_{\mathrm{AD}}$, a characteristic ceiling jet temperature, is the temperature that would be measured adjacent to an adiabatic lower ceiling surface, and $h_{L}$ is a heat transfer coefficient. $h_{L}$ and $T_{A D}$ are given by

$$
\begin{aligned}
& \mathrm{h}_{\mathrm{L}} / \mathrm{h}= \begin{cases}8.82 \mathrm{Re}_{\mathrm{H}}^{-1 / 2} \operatorname{Pr}^{-2 / 3}\left[1-\left(5.0-0.284 \mathrm{Re}_{\mathrm{H}}{ }^{0.2}\right)(\mathrm{r} / \mathrm{H})\right] & \text { if } 0 \leq \mathrm{r} / \mathrm{H}<0.2 ; \\
0.283 \operatorname{Re}_{\mathrm{H}}^{-0.3} \operatorname{Pr}^{-2 / 3}(\mathrm{r} / \mathrm{H})^{-1.2}(\mathrm{r} / \mathrm{H}-0.0771) /(\mathrm{r} / \mathrm{H}+0.279) & \text { if } 0.2 \leq \mathrm{r} / \mathrm{H}\end{cases} \\
& \left(\mathrm{T}_{\mathrm{AD}}-\mathrm{T}_{\mathrm{U}}\right) /\left(\mathrm{T}_{\mathrm{U}} \dot{\mathrm{Q}}_{\mathrm{H}}^{* 2 / 3}\right)= \begin{cases}10.22-14.9 \mathrm{r} / \mathrm{H} & \text { if } 0 \leq \mathrm{r} / \mathrm{H}<0.2 ; \\
8.39 \mathrm{f}(\mathrm{r} / \mathrm{H}) & \text { if } 0.2 \leq \mathrm{r} / \mathrm{H}\end{cases}
\end{aligned}
$$

where

$$
\begin{aligned}
& \mathrm{f}(\mathrm{r} / \mathrm{H})=\left[1-1.10(\mathrm{r} / \mathrm{H})^{0.8}+0.808(\mathrm{r} / \mathrm{H})^{1.6}\right] / \\
& \quad\left[1-1.10(\mathrm{r} / \mathrm{H})^{0.8}+2.20(\mathrm{r} / \mathrm{H})^{1.6}+0.690(\mathrm{r} / \mathrm{H})^{2.4}\right] \\
& \mathrm{r}=\left[\left(\mathrm{X}-\mathrm{X}_{\mathrm{FIRE}}\right)^{2}+\left(\mathrm{Y}-\mathrm{Y}_{\mathrm{FIRE}}\right)^{2}\right]^{1 / 2} \\
& \mathrm{~h}=\rho_{\mathrm{U}} \mathrm{C}_{\mathrm{p}} \mathrm{g}^{1 / 2} \mathrm{H}^{1 / 2} \dot{\mathrm{Q}}_{\mathrm{H}}^{* 1 / 3} ; \mathrm{Re}_{\mathrm{H}}=\mathrm{g}^{1 / 2} \mathrm{H}^{3 / 2} \dot{\mathrm{Q}}_{\mathrm{H}}^{* 1 / 3} / \nu_{\mathrm{U}} ; \dot{\mathrm{Q}}_{\mathrm{H}}^{*}=\dot{\mathrm{Q}}^{\prime} /\left[\rho_{\mathrm{U}} \mathrm{C}_{\mathrm{p}} \mathrm{T}_{\mathrm{U}}(\mathrm{gH})^{1 / 2} \mathrm{H}^{2}\right]
\end{aligned}
$$

In the above, $\operatorname{Pr}$ is the Prandtl number (taken to be 0.7 ) and $\nu_{\mathrm{U}}$ is the kinematic viscosity of the upper layer gas which is assumed to have the properties of air. Also, $\dot{\mathrm{Q}}_{\mathrm{H}}^{*}$, a dimensionless number, is a measure of the strength of the plume and $\mathrm{Re}_{\mathrm{H}}$ is a characteristic Reynolds number of the plume at the elevation of the ceiling. 
The following estimate for $\nu_{U}$ of air [14] will be used when computing $\mathrm{Re}_{\mathrm{H}}$ from Eqs. (18)

$$
v_{U}=\left[0.04128\left(10^{-7}\right) \mathrm{T}_{\mathrm{U}}^{5 / 2}\right] /\left[\mathrm{T}_{\mathrm{U}}+110.4\right] v_{\mathrm{U}} \text { in } \mathrm{m}^{2} / \mathrm{s}, \mathrm{T}_{\mathrm{U}} \text { in } \mathrm{K}
$$

Eqs. (13)-(19) are valid when $Z_{\text {LAYER }}<Z_{\text {CEIL }}$ and $T_{U}$ is well defined. When $Z_{\text {LAYER }}=Z_{\text {CEIL }}$ and $T_{U}$ is undefined, the results are also valid if $T_{U}$ is set equal to $T_{L}$ in these equations. This will yield the correct limiting result for the convective heat transfer to the ceiling, namely, convective heat transfer to the ceiling from an unconfined ceiling jet in a lower layer environment.

Integrating $\dot{\mathrm{q}} \ddot{\mathrm{CEIL}}(\mathrm{X}, \mathrm{Y})$ according to Eq. (2) yields the desired results for $\dot{\mathrm{Q}}_{\mathrm{CEIL}}$ and $\dot{\mathrm{q}} \mathrm{CEIL,AVE}$.

\section{Calculating the Average Convective Heat Transfer to the Upper and Lower Wall Surfaces}

As mentioned above Eq. (2), the ceiling jet is blocked eventually by the relatively cool wall surfaces where ceiling-jet/wall-surface impingement leads to a stagnation-point type of heat transfer enhancement there. In [4] it is estimated that for fires relatively close to a wall (i.e., a wall near to, but outside, the presently restricted $\mathrm{r} / \mathrm{H}=0.2$ circle, where ceiling jet velocities are at or near to their largest amplitudes) the rate of heat transfer to the wall, $\dot{q}_{w A L L}$ is more than two times that of the jet-to-local-ceiling-surface heat transfer.

Locations of Normal Ceiling-Jet/Wall Impingement. For the fire scenarios being studied here, there are four locations where ceiling-jet/wall impingement involves ceiling jet velocities normal to the wall. These locations are identified in Figure 1 as STP1, STP2, STP3, and STP4. At such stagnation points, i.e., at the ceiling/wall junction, an estimate of the heat transfer to the wall is [4]

$$
\dot{\mathrm{q}}_{\mathrm{WALL}, \mathrm{ST}}=\mathrm{h}_{\mathrm{ST}}\left(\mathrm{T}_{\mathrm{AD}}-\mathrm{T}_{\mathrm{WALL}}\right)
$$

where

$$
\mathrm{h}_{\mathrm{ST}} / \bar{h}=0.94 \mathrm{Re}_{\mathrm{H}}^{-0.42} /\left[\left(\mathrm{r}_{\mathrm{ST}} / \mathrm{H}\right) \mathrm{Pr}\right]
$$

$\mathrm{r}_{\mathrm{ST}}$ is the value of $\mathrm{r}$ of Eq. (16) at the stagnation point (e.g., $\mathrm{r}_{\mathrm{ST}}=\mathrm{Y}_{\mathrm{FIRE}}$ for STP1 in Figure 1), and $\mathrm{T}_{\mathrm{AD}}, \bar{h}$, and $\mathrm{Re}_{\mathrm{H}}$ are given in Eqs. (15) and (17).

In [5] it is estimated that at locations of normal jet/wall impingement the penetration depth of the downward-directed wall flow is approximately $0.8 \mathrm{H}$ or $\mathrm{Z}_{\mathrm{CEIL}}$ (i.e., penetration to the floor), whichever is smaller, and that this result is relatively invariant with the value of $r_{S T} / H$. Here it is assumed that the heat transfer goes to zero at this penetration depth, and remains zero below this elevation. It is assumed further, that the heat transfer to the wall is linear with elevation, going from quaLL,ST at the ceiling to zero at $\mathrm{Z}=\mathrm{Z}_{\mathrm{CEIL}}-0.8 \mathrm{H}$. (It is possible for the latter elevation to be negative, i.e., below the floor, because of the fact that when the fire is in the lower layer, $\mathrm{H}$ is based on the 
elevation of an equivalent point source of buoyancy in the extended upper layer. Consistant with the inequality of Eq. (10), this elevation can actually be below the floor elevation, $Z=0$. When such is the case, the assumed linear distribution for wall heat transfer is only used between the floor and ceiling elevations.

The above paragraph leads to the following estimate for the average convective heat transfer on the upper wall segment (between $\mathrm{Z}_{\mathrm{CEIL}}$ and $\mathrm{Z}_{\text {LAYER }}$ ), $\dot{\text { q }}$ WALL,NORM,U , and on the lower wall segment (between $Z_{\text {LAYER }}$ and the floor), $\dot{q}$ WALL,NORM,L, along vertical lines on a wall where normal ceilingjet/wall impingement occurs:

$$
\begin{aligned}
& 0.8 \mathrm{H}<\mathrm{Z}_{\mathrm{CEIL}}-\mathrm{Z}_{\mathrm{LAYER}} \\
& \dot{\mathrm{q}}_{\mathrm{WALL}, \mathrm{NORM}, \mathrm{U}}^{\prime \prime}=\left(\dot{\mathrm{q}}_{\mathrm{WALL}, \mathrm{ST}} / 2\right)\left(\mathrm{Z}_{\mathrm{CEIL}} \cdot 0.8 \mathrm{H}\right) /\left(\mathrm{Z}_{\mathrm{CEIL}}-\mathrm{Z}_{\mathrm{LAYER}}\right)
\end{aligned}
$$

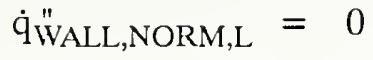

$$
\begin{aligned}
& \mathrm{Z}_{\text {CEIL }}-\mathrm{Z}_{\mathrm{LAYER}} \leq 0.8 \mathrm{H}<\mathrm{Z}_{\mathrm{CEIL}} \text { : } \\
& \dot{q}_{W A L L, N O R M, U}^{\prime \prime}=\dot{q}_{W A L L, S T}^{\prime \prime}\left[1-\left(Z_{\text {CEIL }}-Z_{\text {LAYER }}\right) /(1.6 \mathrm{H})\right] \\
& \dot{\mathrm{q}}_{\mathrm{WALL}, \mathrm{NORM}, \mathrm{L}}=\left(\dot{\mathrm{q}}_{\mathrm{W}}{ }_{\mathrm{WALL}, \mathrm{ST}} / 2\right)\left[0.8 \mathrm{H}-\left(\mathrm{Z}_{\mathrm{CEIL}}-\mathrm{Z}_{\mathrm{LAYER}}\right)\right] / \mathrm{Z}_{\mathrm{LAYER}} \\
& \mathrm{Z}_{\mathrm{CEIL}} \leq 0.8 \mathrm{H} \text { : } \\
& \dot{q}_{\mathrm{WALL}, \mathrm{NORM}, \mathrm{U}}=\dot{\mathrm{q}}_{\mathrm{WALL}, \mathrm{ST}}\left[1-\left(\mathrm{Z}_{\mathrm{CEIL}}-\mathrm{Z}_{\mathrm{LAYER}}\right) /(1.6 \mathrm{H})\right] \\
& \dot{\mathrm{q}}_{\text {WALL,NORM,L }}^{\prime \prime}=\left(\dot{\mathrm{q}}_{\mathrm{WALL}, \mathrm{ST}}^{\prime \prime} / 2\right)\left[1.6 \mathrm{H}-\left(\mathrm{Z}_{\mathrm{CEIL}}-\mathrm{Z}_{\mathrm{LAYER}}\right)-\mathrm{Z}_{\mathrm{CEIL}}\right] /(0.8 \mathrm{H})
\end{aligned}
$$

Strategy for Estimating Heat Transfer to the Walls. As noted, Eqs. (22)-(27) can be applied to vertical lines passing through points STP1, STP2, STP3, and STP4. The following strategy is adopted for estimating the average rate of ceiling-jet-driven convective heat transfer to the upper and lower layer wall segments of the room:

1. Use Eqs. (20) and (21) to calculate $\dot{q}_{W A L L}$ at the top of the walls near the points STP1, STP2, STP3, and STP4. Then use Eqs. (22)-(27) to calculate the average $\dot{q}_{\text {WALL }}$ along the upper- and lower-layer segments of vertical lines through these points.

2. Estimate $\dot{q}_{W A L L}$ at the top of the walls near the four room corners of the room by assuming normal ceiling-jet/wall impingement there and using Eqs. (20) and (21). For example, use these 
equations with $\mathrm{r}_{\mathrm{ST}}=\left(\mathrm{X}_{\mathrm{FIRE}}^{2}+\mathrm{Y}_{\mathrm{FIRE}}^{2}\right)^{1 / 2}$ to estimate the heat ransfer near the top of the walls at $\mathrm{X}=\mathrm{Y}=0$. Then use Eqs. (22)-(27) to calculate the average $\dot{\mathrm{q}}_{\text {WALL }}$ along the upper- and lower-layer segments of the vertical lines which define these corners.

3. For an upper or lower wall segment between STP1, STP2, STP3, or STP4, and an adjacent corner, estimate the average value of $\dot{q}_{W A L L}^{\prime \prime}$ as the average of the previously computed average values along the vertical bounding "end-lines." Calculate this average for each of the eight upper segments and eight lower segments.

4. For each of the upper-layer segments use the area of the segment and the previously calculated average $\dot{q}$ wALL to calculate the eight contributions to the total rate of upper-layer wall heat transfer. Sum these contributions and obtain finally $\dot{q}_{w A L L, U, A V E}$, the average flux of heat transfer to the upper-layer portions of the walls. Carry out analogous calculations for $\dot{q}{ }_{W A L L}, \mathrm{~L}, \mathrm{AVE}$, the average flux of heat transfer to the lower-layer portions of the walls.

5. Add the rates of heat transfer to all sixteen upper and lower wall segments and obtain, $\dot{Q}_{\text {WALL }}$, the total rate of heat transfer to the wall surfaces.

The details of the above algorithm are presented in Appendix A.

It is important to point out that in compartment fires there are fluid dynamic effects other than ceiling-jet/wall impingement that can lead to, and dominate the convective heat transfer to walls (see, e.g. [6] and [15]). These effects are not considered in this work.

\section{The Computer Subroutine CEILIT for Carrying out the Heat Transfer Calculations}

The model equations of the last two sections were used to develop an algorithm and associated modular computer subroutine to carry out the indicated heat transfer calculations. The subroutine is written in FORTRAN 77 and is called CEILHT. A summary flow diagram for the algorithm is presented in Figure 3. The algorithm and subroutine are suitable for use in two-layer zone-type compartment fire model computer codes.

CEILHT, which uses the two-dimensional numerical integration subroutine ADAPT [16], is presented in Appendix B. CEILHT has been tested for a variety of instantaneous fire environments involving a $10^{7} \mathrm{~W}$ fire in a $8 \mathrm{~m} \times 8 \mathrm{~m} \times 4 \mathrm{~m}$ high enclosure. While the calculated results were plausible, it is important to point out that CEILHT simulations have not been experimentally validated.

\section{Velocity and Temperature Distributions in the Ceiling Jet}

It is an objective of this work to simulate the velocity and temperature distributions in the ceiling jet. The major interest is to develop a general capability for predicting the dynamic environment local to near-ceiling-deployed fire safety devices, e.g. fusible sprinkler links. Knowledge of this environment would be used in predictions of their thermal response to the fire-generated environment (see, e.g., [13] and [17]). 
For relatively smooth-ceiling configurations, assumed to be representative of the rooms of fire origin studied in this work, the ceiling jet flows outward radially from the point of plume/ceiling impingement and its gas velocity and temperature distributions, $V_{C J}$ and $T_{C J}$, respectively, are a function of radius from the impingement point, $r$, distance below the ceiling, $z$, and time. Note that it has been shown with some generality that plume-driven ceiling jets are inertially dominated flows from small to moderate $\mathrm{r} / \mathrm{H}$ values [18].

The Velocity Distribution. Let $\mathrm{z}$ be the distance downward from the ceiling surface, i.e., if $\mathrm{Z}$ is the elevation above the floor,

$$
\mathrm{z}=\mathrm{Z}_{\mathrm{CEIL}}-\mathrm{Z}
$$

Define the plume/ceiling impingement stagnation zone by $\mathrm{r} / \mathrm{H}<0.2$. Outside the stagnation zone and at a given $r, V_{C J}$ rises rapidly from zero at the ceiling's lower surface, $z=0$, to a maximum, $\mathrm{V}_{\mathrm{MAX}}$, at a distance $\mathrm{z}=0.23 \delta, \delta(\mathrm{r})$ being the distance below the ceiling where $\mathrm{V} / \mathrm{V}_{\mathrm{MAX}}=1 / 2[5]$. In this region outside the stagnation zone, $\mathrm{V}_{\mathrm{CJ}}$ can be estimated from [5]

When $\mathrm{r} / \mathrm{H} \geq 0.2$ :

$$
\begin{aligned}
& \mathrm{V}_{\mathrm{CJ}} / \mathrm{V}_{\mathrm{MAX}}= \begin{cases}(8 / 7)[\mathrm{z} /(0.23 \delta)]^{1 / 7}\{1-[\mathrm{z} /(0.23 \delta)] / 8\} & \text { if } 0 \leq \mathrm{z} /(0.23 \delta) \leq 1 ; \\
\cosh ^{-2}\left\{(0.23 / 0.77) \operatorname{arccosh}\left(2^{1 / 2}\right)[\mathrm{z} /(0.23 \delta)-1]\right\} & \text { if } 1 \leq \mathrm{z} /(0.23 \delta)\end{cases} \\
& \mathrm{V}_{\mathrm{MAX}} / \mathrm{V}=0.85(\mathrm{r} / \mathrm{H})^{-1.1} ; \delta / \mathrm{H}=0.10(\mathrm{r} / \mathrm{H})^{0.9} ; \mathrm{V}=\mathrm{g}^{1 / 2} \mathrm{H}^{1 / 2} \dot{\mathrm{Q}}_{\mathrm{H}}^{* 1 / 3}
\end{aligned}
$$

where $\dot{Q}_{\mathrm{H}}^{*}$ is defined in Eq. (18). $\mathrm{V}_{\mathrm{CJ}} / \mathrm{V}_{\text {MAX }}$ per Eq. (29) is plotted in Figure 4.

Inside the stagnation zone, the fire-driven flow is changing directions from an upward-directed plume flow to a outward-directed ceiling-jet-type flow. There the flow velocity involves generally a significant vertical as well as radial component of velocity with the characteristic velocity being the maximum ceiling jet velocity at $\mathrm{r} / \mathrm{H}=0.2$

$$
\begin{aligned}
& \text { When } 0 \leq \mathrm{r} / \mathrm{H}<0.2 \text { : } \\
& \left|\mathrm{V}_{\mathrm{CJ}}\right|=\text { Order of }\left[\mathrm{V}_{\mathrm{CJ}}(\mathrm{r} / \mathrm{H}=0.2)\right]
\end{aligned}
$$

Other considerations are required for a more accurate description of the velocity in the stangnation zone. 
The Temperature Distribution. Outside of the stagnation zone, i.e., where $\mathrm{r} / \mathrm{H} \geq 0.2$, and at a given value of $r, T_{C J}$ changes very rapidly from the temperature of the ceiling's lower surface $T_{C E I L}$, at $z$ $=0$, to a local maximum, $\mathrm{T}_{\mathrm{MAX}}$, somewhat below the ceiling surface. We assume that this maximum value of $\mathrm{T}_{\mathrm{CJ}}$ occurs at the identical distance below the ceiling as does the maximum of $\mathrm{V}_{\mathrm{CJ}}$, i.e., at $z=0.23 \delta$. Below this elevation, $T_{C J}$ drops with increasing distance from the ceiling until it reaches the upper layer temperature, $\mathrm{T}_{\mathrm{U}}$. In this latter outer region of the ceiling jet, the shape of the normalized $\mathrm{T}_{C J}$ distribution, $\left(\mathrm{T}_{\mathrm{CJ}}-\mathrm{T}_{\mathrm{U}}\right) /\left(\mathrm{T}_{\mathrm{MAX}}-\mathrm{T}_{\mathrm{U}}\right)$, will have the same characteristics as does that of $\mathrm{V}_{\mathrm{CJ}} / \mathrm{V}_{\mathrm{MAX}}$. Also, since we are dealing with a turbulent boundary flow it is reasonable to expect that the characteristic thicknesses of the outer region of both the velocity and temperature distributions are the same, being dictated there by the distribution of the turbulent eddies.

For the above reasons we approximate the velocity and temperature distributions as being identical in the outer region of the ceiling jet flow, $0.23 \delta \leq \mathrm{z}$. In the inner region of the flow, between $\mathrm{z}=$ 0 and $0.23 \delta$, we approximate the normalized temperature distribution by a quadratic function of $\mathrm{z} /(0.23 \delta)$, requiring $\mathrm{T}_{\mathrm{CJ}}=\mathrm{T}_{\text {CEIL }}$ at $\mathrm{z}=0$ and $\mathrm{T}_{\mathrm{CJ}}=\mathrm{T}_{\mathrm{MAX}}, \partial \mathrm{T}_{\mathrm{CJ}} / \partial \mathrm{z}=0$ at $\mathrm{z}=0.23 \delta$. Thus,

When $\mathrm{r} / \mathrm{H} \geq 0.2$ :

$$
\begin{aligned}
& \Theta \equiv\left(\mathrm{T}_{\mathrm{CJ}}-\mathrm{T}_{\mathrm{U}}\right) /\left(\mathrm{T}_{\mathrm{MAX}} \mathrm{T}_{\mathrm{U}}\right)= \begin{cases}\Theta_{\mathrm{S}}+2\left(1-\Theta_{\mathrm{S}}\right)[\mathrm{z} /(0.23 \delta)]-\left(1-\Theta_{\mathrm{S}}\right)[\mathrm{z} /(0.23 \delta)]^{2} \\
\mathrm{~V}_{\mathrm{CJ}} / \mathrm{V}_{\mathrm{MAX}} & \text { if } 0 \leq \mathrm{z} /(0.23 \delta) \leq 1\end{cases} \\
& \Theta_{\mathrm{S}} \equiv \Theta\left(\mathrm{T}_{\mathrm{CJ}}=\mathrm{T}_{\mathrm{CEIL}}\right)=\left(\mathrm{T}_{\mathrm{CEIL}}-\mathrm{T}_{\mathrm{U}}\right) /\left(\mathrm{T}_{\mathrm{MAX}}-\mathrm{T}_{\mathrm{U}}\right)
\end{aligned}
$$

Note that $\Theta_{S}$ will be negative where the ceiling surface temperature is less than the upper layer temperature, for example, relatively early in the fire when the original ambient-temperature ceiling surface has not yet reached the average temperature of the growing upper layer. Also, $\Theta_{S}$ will be greater than 1 where the ceiling surface temperature is greater than $\mathrm{T}_{\mathrm{MAX}}$. This is possible, for example, during times of reduced fire size when the fire's near-ceiling plume temperature is reduced significantly, perhaps temporarily, from previous values, but the ceiling surface, heated previously to relatively high temperatures, has not cooled substantially. Plots of $\Theta$ per Eq. (32) are presented in Figure 5 for cases when $\Theta_{S}$ is $<0$, between 0 and 1 , and $>0$.

In order to calculate $T_{C J}(r, z)$ from Eq. (32), it is necessary to determine the one unknown parameter, $\mathrm{T}_{\mathrm{MAX}}(\mathrm{r})$. This is obtained by invoking conservation of energy. Thus, at an arbitrary $\mathrm{r}$ outside the stagnation zone, the total rate of radial outflow of enthalpy (relative to the upper layer temperature) of the ceiling jet within a small subtended angle $\Delta \theta$ is equal to the fraction $\Delta \theta /(2 \pi)$ of the rate of enthalpy flow in the upper layer portion of the plume, Q', less the integral (from the plume-ceiling impingement point to $r$ ) of the flux of convective heat transfer from the ceiling jet to the ceiling surface, i.e., 
When $0.2 \leq \mathrm{r} / \mathrm{H}$ :

$$
2 \pi \mathrm{r} \int_{0}^{\infty} \rho_{\mathrm{U}} \mathrm{C}_{\mathrm{p}}\left(\mathrm{T}_{\mathrm{CJ}}-\mathrm{T}_{\mathrm{U}}\right) \mathrm{V}_{\mathrm{CJ}} \mathrm{dz}=\dot{\mathrm{Q}}^{\prime}-2 \pi \int_{0}^{\mathrm{r}} \ddot{\mathrm{q}}_{\mathrm{CEIL}}(\mathrm{r}) \mathrm{rdr} \equiv\left(1-\lambda_{\mathrm{CONV}}\right) \dot{\mathrm{Q}}^{\prime}
$$

where $\lambda$ CONV(r) is the fraction of Q' subtended by $\Delta \theta$ and transferred by convection to the ceiling from the point of ceiling impingement to $r$, i.e.,

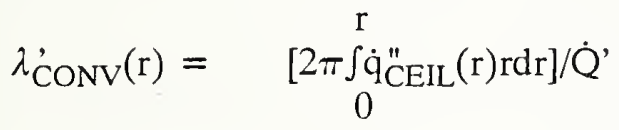

In the above, Q' has been calculated previously in Eqs. (11'). Also, for particular r's of interest, and with $\dot{q}_{\text {CEIL }}^{\prime \prime}$ evaluated according to Eqs. (13)-(19), the integral on the right hand sides of Eqs. (34) and (35) can be determined numerically.

The integral on the left hand side of Eq. (34) is calculated using $\mathrm{V}_{\mathrm{CJ}}$ of Eqs. (29) and (30) and $\mathrm{T}_{\mathrm{CJ}}$ of Eqs. (32) and (33). From this the desired distribution for $T_{\text {MAX }}$ is found finally to be [13]

$$
\left(\mathrm{T}_{\mathrm{MAX}}-\mathrm{T}_{\mathrm{U}}\right)=2.6\left(1-\lambda_{\mathrm{CONV}}\right)(\mathrm{r} / \mathrm{H})^{-0.8} \dot{\mathrm{Q}}_{\mathrm{H}}^{* 2 / 3} \mathrm{~T}_{\mathrm{U}}-0.090\left(\mathrm{~T}_{\mathrm{CEIL}}-\mathrm{T}_{\mathrm{U}}\right) \text { if } 0.2 \leq \mathrm{r} / \mathrm{H}
$$

The above result together with Eqs. (32) and (33) represent the desired estimate for $\mathrm{T}_{\mathrm{CJ}}(\mathrm{r}, \mathrm{z})$.

\section{Summary}

This work presented a model to predict the instantaneous rate of convective heat transfer from fire plume gases to the overhead ceiling surface in a room of fire origin. The room is assumed to be a rectangular parallelopiped and, at times of interest, ceiling temperatures are simulated as being uniform. Also presented is an estimate of the convective heat transfer, due to ceiling-jet-driven wall flows, to the wall surfaces. The effect on the heat transfer of the location of the fire within the room is taken into account. Finally presented was a model of the velocity and temperature distributions in the ceiling jet.

The model equations were used to develop an algorithm and associated modular computer subroutine to carry out the indicated heat transfer calculations. The subroutine is written in FORTRAN 77 and is called CEILHT. A summary flow diagram for the algorithm is presented in Figure 3. The algorithm and subroutine are suitable for use in two-layer zone-type compartment fire model computer codes. CEILHT, which uses the two-dimensional numerical integration subroutine ADAPT [16] is presented in Appendix B. CEILHT has been tested for a variety of instantaneous fire environments involving a $10^{7} \mathrm{~W}$ fire in a $8 \mathrm{~m} \times 8 \mathrm{~m}$ x $4 \mathrm{~m}$ high enclosure. While the calculated results were plausible, it is important to point out that CEILHT simulations have not been experimentally validated. 


\section{Acknowledgements}

The author is pleased to acknowledge that the work described here was carried out with the support of the US Nuclear Regulatory Commission. Also, Dr. Glenn P. Forney was helpful in identifying the appropriate integration software, ADAPT, used in CEILHT, and in modifying ADAPT for double precision computations. 
Nomenclature

\begin{tabular}{|c|c|}
\hline $\mathrm{A}_{\text {WALL,L,N }}\left[\mathrm{A}_{\text {WALL,U,N }}\right]$ & area of lower- [upper-] layer portion of wall segment $N$ \\
\hline $\mathrm{C}_{\mathrm{p}}$ & specific heat at constant pressure \\
\hline $\mathrm{C}_{\mathrm{T}}$ & 9.115 \\
\hline $\mathrm{f}(\mathrm{r} / \mathrm{H})$ & Eq. (16) \\
\hline g & acceleration of gravity \\
\hline $\mathrm{H}$ & distance of continuation source below ceiling, Eq. (10) \\
\hline h & a characteristic heat transfer coefficient, Eq. (8) \\
\hline$h_{L}$ & heat transfer coefficient, Eq. (14) \\
\hline $\mathrm{h}_{\mathrm{ST}}$ & heat transfer coefficient at wall stagnation point, Eq. (21) \\
\hline$\dot{\mathrm{M}}^{*}$ & fraction of $\dot{\mathrm{M}}_{\text {PLUME }}$ which is buoyant in upper layer, Eq. (7) \\
\hline$\dot{\mathrm{M}}_{\text {PLUME }}$ & mass flow rate in plume at $Z_{\text {LAYER }}$ when $Z_{\text {FIRE }}<Z_{\text {LAYER }}$ \\
\hline $\operatorname{Pr}$ & Prantl number \\
\hline Q' & strength of continuation source, Eq. (11') \\
\hline$Q_{\text {CEIL }}$ & rate of heat transfer to ceiling, Eq. (2) \\
\hline $\mathrm{Q}_{\mathrm{EQ}}^{*}$ & dimensionless strength of plume at $Z_{\text {LAYER }}$ \\
\hline$Q_{\mathrm{H}}^{*}$ & dimensionless strength of plume at $\mathrm{Z}_{\mathrm{CEIL}}$ \\
\hline $\mathrm{Q}_{\mathrm{FCONV}}$ & portion of fire energy release rate convected in plume \\
\hline$Q_{\text {PLUME }}$ & flow of enthalpy in plume at $\mathrm{Z}_{\mathrm{LAYER}}$, Eq. (1) \\
\hline$Q_{\text {WALL }}$ & rate of heat transfer to all wall surfaces. Eq. (A-6) \\
\hline q́ं̈EIL & flux of rate of heat transfer to ceiling, Eq. (13) \\
\hline$\dot{q}_{\text {CEIL,AVE }}^{\prime \prime}$ & average flux of rate of heat transfer to ceiling, Eq. (2) \\
\hline q̊ẄWLL & flux of heat transfer to the wall \\
\hline$\dot{\mathrm{q}}=\mathbf{W A L L}, \mathrm{CRNN}, \mathrm{L}\left[\dot{q}_{W A L L, C R N N, U}\right]$ & average qُwALL near corner $\mathrm{N}$ in lower [upper] layer \\
\hline
\end{tabular}




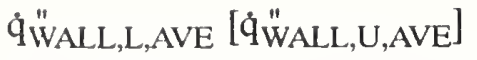

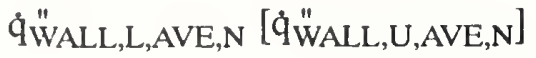

qٔWALL,NORM,L [qْW"WLL,NORM,U]

q̊ẄALL,ST

qٔWaLL,STPN,L [qْW"WLLL,STPN,U]

$\mathrm{Re}_{\mathrm{H}}$

r

${ }^{\mathrm{CRNN}}$

$\mathrm{r}_{\mathrm{ST}}$

$\mathrm{r}_{\text {STPN }}$

$\mathrm{T}_{\mathrm{AD}}$

$\mathrm{T}_{\text {CEIL }}$

$\mathrm{T}_{\mathrm{CI}}$

$\mathrm{T}_{\mathrm{L}}, \mathrm{T}_{\mathrm{U}}$

$\mathrm{T}_{\text {WALL }}$

V

$\mathrm{V}_{\mathrm{CJ}}$

$\mathrm{V}_{\text {MAX }}$

$\mathrm{X}, \mathrm{Y,Z}$

$\mathrm{X}_{\text {WALL }}, \mathrm{Y}_{\mathrm{WALL}}$, and $\mathrm{Z}_{\mathrm{CEIL}}$

$\mathrm{X}_{\text {FIRE}}, \mathrm{Y}_{\text {FIRE }}$, and $\mathrm{Z}_{\text {FIRE }}$

$\mathrm{Z}_{\mathrm{EQ}}$ average $\dot{q}_{\text {WALL }}$ portion of wall in lower [upper] layer, Eq. (A-5)

average $\dot{q}_{\text {WALL }}^{\|}$to portion of wall segment $\mathrm{N}$ in the lower [upper] layer

average $\dot{q}_{\text {WALL }}$ to lower- [upper-] layer portion of wall near vertical line through ceiling-jet/wall stagnation point

$\mathfrak{q}_{\text {WALL }}$ at a ceiling-jet/wall stagnation point, Eq. (20)

average $\dot{q}_{\text {WALL }}^{\|}$to portion of wall in the lower- [upper-] layer along the line passing through stagnation point N (STPN)

characteristic Reynolds number, Eq. (18)

distance from plume/ceiling impingement point

r of corner $N(C R N N)$

r of a stagnation point

r of stagnation point $\mathrm{N}(\mathrm{STPN})$

adiabatic ceiling jet temperature, Eq. (15)

temperature of ceiling

temperature of ceiling jet

temperature of lower [upper] layer

average temperature of the wall surfaces

characteristic velocity of ceiling jet, Eq. (30)

velocity of ceiling jet, Eq. (29)

maximum velocity of ceiling jet, Eq. (30)

co-ordinates in room, origin at a room corner on the floor

$\mathrm{X}, \mathrm{Y}, \mathrm{Z}$ of room corner diagonal from origin

$\mathrm{X}, \mathrm{Y}, \mathrm{Z}$ of center of base of fire

$\mathrm{Z}$ of equivalent source in lower layer, Eq. (6) 
$Z_{\text {LAYER }}$

Z $_{\text {SOURCE }}$

Z

$\alpha$

$\delta$

$\Theta$

$\Theta_{\mathrm{S}}$

$\lambda_{\text {CONV }}$

$v_{U}$

$\rho_{\mathrm{L}}, \rho_{\mathrm{U}}$

$\sigma$
$\mathrm{Z}$ of layer interface

$\mathrm{Z}$ of continuation source, Eq. (12)

distance below ceiling surface, Eq. (28)

$\mathrm{T}_{\mathrm{U}} / \mathrm{T}_{\mathrm{L}}$

characteristic ceiling jet thickness, Eq. (30)y

dimensionless $\mathrm{T}_{\mathrm{CJ}}$, Eq. (32)

$\Theta$ at ceiling surface

Eq. (35)

kinematic viscosity of air, Eq. (19)

average density of lower [upper] layer

dimensionless parameter, Eq. (9) 
[1] Tanaka, T., A Model of Multiroom Fire Spread, NBSIR 83-2718, National Institute of Standards and Technology (formerly U.S. National Bureau of Standards), Gaithersburg MD, 1983.

[2] Jones, W.W., A Multicompartment Model for the Spread of Fire, Smoke, and Toxic Gases, Fire Safety Journal, Vol. 9, pp. 55-79, 1985.

[3] Mitler, H.E. and Rockett, J.A., User's Guide to FIRST, A Comprehensive Single-Room Fire Model, NBSIR 87-3595, National Institute of Standards and Technology (formerly U.S. National Bureau of Standards), Gaithersburg MD, 1987.

[4] Cooper, L.Y., Heat Transfer in Compartment Fires Near Regions of Ceiling-Jet Impingement on a Wall, Journal of Heat Transfer, 111, pp.455-460, 1989.

[5] Cooper, L.Y., Ceiling Jet-Driven Wall Flows in Compartment Fires, Combustion Science and Technology, Vol. 62, pp. 285-296, 1988.

[6] Jaluria, Y. and Cooper, L.Y., Negatively Buoyant Wall Flows Generated in Enclosure Fires, Progress in Energy and Combustion Science, 15, pp. 159-182, 1989.

[7] Zukoski, E.E., Kubota, T., and Cetegen, B., Fire Safety Journal, 3, p 107, 1981.

[8] Cooper, L.Y., A Buoyant Source in the Lower of Two, Homogeneous, Stably Stratified Layers, 20th International Symposium on Combustion, Combustion Institute, pp. 1567-1573, 1984.

[9] Cooper, L.Y., Convective Heat Transfer to Ceilings Above Enclosure Fires, Cooper, L.Y., 19th Symposium (International) on Combustion, Combustion Institute, pp. 933-939 (1982).

[10] Cooper, L.Y., Heat Transfer From a Buoyant Plume to an Unconfined Ceiling, Journal of Heat Transfer, Vol. 104, pp. 446-451, Aug. 1982.

[11] Cooper, L.Y. and Woodhouse, A. The Buoyant Plume-Driven Adiabatic Ceiling Temperature Revisited, Journal of Heat Transfer, Vol. 108, pp. 822-826, Nov., 1986.

[12] Cooper, L.Y., and Stroup, D.W., Thermal Response of Unconfined Ceilings Above Growing Fires and the Importance of Convective Heat Transfer, Journal of Heat Transfer, Vol. 109, pp. 172-178, Feb. 1987.

[13] Cooper, L.Y., Estimating the Environment and the Response of Sprinkler Links in Compartment Fires with Draft Curtains and Fusible Link-Actuated Ceiling Vents - Theory, Fire Safety Journal, 16, pp. 137-163, 1990.

[14] Hilsenrath, J., Tables of Thermal Properties of Gases, Circular 564, National Bureau of Standards, Gaithersburg, MD, Nov. 1955. 
[15] Cooper, L.Y., On the Significance of a Wall Effect in Enclosures with Growing Fires, Combustion Science and Technology, 40, pp. 19-39, 1984.

[16] Genz, A.C. and Malik, A.A., Algorithm 019: An Adaptive Algorithm for Numerical Integration Over An N-Dimensional Rectangular Region, Journal of Computational and Applied Mathematics, 6, pp. 295-299, 1980.

[17] Davis, W.D. and Cooper, L.Y., Estimating the Environment and the Response of Sprinkler Links in Compartment Fires with Draft Curtains and Fusible Link-Actuated Ceiling Vents: Part II - User Guide for the Computer Code LAVENT, NISTIR 89-4122, National Institute of Standards and Technology, Gaithersburg, 1989.

[18] Alpert, R.L., Turbulent Ceiling Jet Induced by Large-Scale Fires, Combustion Science and Technology, 11, pp. 197-213, 1975. 

Transfer to the Upper and Lower Layer Walls

1. Use Eqs. (20) and (21) to calculate qümall at the top of the walls near the points STP1, STP2, STP3, and STP4. Then use Eqs. (22)-(27) to calculate the average q" "WALL along the upper- and lower-layer segments of the vertical lines through these points.

Refer to Figure 6. Designate the radii of points STP1, STP2, etc. as $r_{\mathrm{STP} 1}$, $\mathrm{r}_{\mathrm{STP}}$, etc., respectively, and calculate their values:

$$
\begin{aligned}
& r_{\text {STP1 }}=Y_{\text {FIRE }} \\
& r_{\text {STP2 }}=X_{\text {WALL }}-X_{\text {FIRE }} \\
& r_{\text {STP3 }}=Y_{\text {WALL }}-Y_{\text {FIRE }} \\
& r_{\text {STP4 }}=X_{\text {FIRE }}
\end{aligned}
$$

Use $r_{\mathrm{STP} 1}$ as $\mathrm{r}_{\mathrm{ST}}$ in Eq. (21) and as $\mathrm{r}$ in Eqs. (15) and (17) and determine the corresponding value of $\dot{q}_{\text {WALL }}$ from Eq. (20). Use this latter value as $\dot{q}_{\text {WALL }, S T}$ in Eqs. (22)-(27) and calculate the desired average heat transfer along the upper and lower line segment through point STP1. Designate these as $\dot{q}_{\text {WALL,STP1,U }}^{\prime \prime}$ and $\dot{q}_{\text {WALL,STP1,L }}^{\prime \prime}$, respectively. Carry out analogous calculations and designations for the STP2, STP3, and STP4.

2. Estimate $\dot{q}_{W A L L}$ at the top of the walls near the four corners of the room by assuming that the effect of concentration of the wall flows there can be simulated by normal ceiling-jet/wall impingement, i.e., by using Eqs. (20) and (21). For example, use these equations with $\mathrm{r}_{\mathrm{ST}}=$ $\left(\mathrm{X}_{\mathrm{FIRE}}^{2}+\mathrm{Y}_{\mathrm{FIRE}}^{2}\right)^{1 / 2}$ to estimate the heat ransfer near the top of the walls near $\mathrm{X}=\mathrm{Y}=0$. Then use Eqs. (22)-(27) to calculate the average q"wALL along the upper- and lower-layer segments of the vertical lines which define these corners.

Refer to Figure 6. Designate the radii to the four room corners, CRN1, CRN2, CRN3, and CRN4 as $\mathrm{r}_{\mathrm{CRN} 1}, \mathrm{r}_{\mathrm{CRN} 2}$, etc., respectively, and calculate their values:

$$
\begin{aligned}
& r_{C R N 1}=\left(X_{\text {FIRE }}^{2}+Y_{\text {FIRE }}^{2}\right)^{1 / 2} \\
& r_{C R N 2}=\left[\left(X_{\text {WALL }}-X_{\text {FIRE }}\right)^{2}+Y_{\text {FIRE }}^{2}\right]^{1 / 2} \\
& r_{C R N 3}=\left[\left(X_{\text {WALL }}-X_{\text {FIRE }}\right)^{2}+\left(Y_{\text {WALL }}-Y_{\text {FIRE }}\right)^{2}\right]^{1 / 2} \\
& r_{C R N 4}=\left[X_{\text {FIRE }}^{2}+\left(Y_{\text {WALL }}-Y_{\text {FIRE }}\right)^{2}\right]^{1 / 2}
\end{aligned}
$$


Replace $r_{S T}$ in Eq. (21) and $r$ in Eqs. (15) and (17) by $r_{C R N 1}$ and determine the corresponding value of q́wALL from Eq. (20). Replace qüHAL,ST in Eqs. (22)-(27) by this latter value and calculate the desired average rates of heat transfer along the upper-and lower-layer CRN1 line segment. Designate these as $\dot{q}_{W A L L, C R N 1, U}^{\prime \prime}$ and $\dot{q}_{W A L L, C R N 1, L}^{\prime}$, respectively. Carry out analogous calculations and designations for the CRN2, CRN3, and CRN4.

3. For an upper- or lower-layer wall segment between STP1, STP2, STP3, or STP4, and an adjacent corner, estimate the average value of quALL $_{\text {as }}$ the average of the previously determined average values along the vertical bounding "end-lines." Calculate this average for each of the eight upper-layer segments and eight lower-layer segments.

Refer to Figure 6. Number the eight pair of upper- and lower-layer wall segments as shown. Designate the average rates of heat transfer to upper- and lower-layer segment 1 as qैWALL,U,AVE,1 and qُWALL,L,AVE,1, respectively. Desigate analogous rates of heat transfer to the other seven pair of wall segments. Calculate:

$$
\begin{aligned}
& \text { q́WALL,U,AVE, } 1=\left(\dot{q} \text { WALL,CRN1,U }+\dot{q}_{\text {WALL,STP1,U }}^{\prime \prime}\right) / 2
\end{aligned}
$$

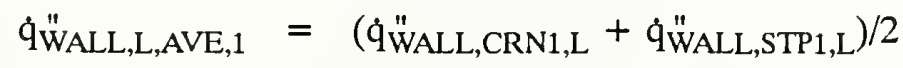

$$
\begin{aligned}
& \text { qٔWALL,U,AVE,2 }=\left(\dot{q} \text { WALL,CRN2,U }+\dot{q}_{\text {WALL }, S T P 1, U}\right) / 2 \\
& \dot{\mathrm{q}}_{\mathrm{WALL}, \mathrm{L}, \mathrm{AVE}, 2}=\left(\dot{\mathrm{q}}_{\mathrm{WALL}, \mathrm{CRN} 2, \mathrm{~L}}+\dot{\mathrm{q}}_{\mathrm{WALL}, \mathrm{STP} 1, \mathrm{~L}}\right) / 2
\end{aligned}
$$

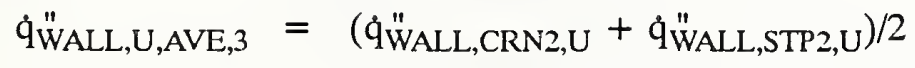

$$
\begin{aligned}
& \dot{q}_{W A L L, L, A V E, 3}^{\prime \prime}=\left(\dot{q}_{W A L L, C R N 2, L}^{\prime \prime}+\dot{q}_{W A L L, S T P 2, L}\right) / 2 \\
& \dot{q} \dot{q}_{W A L L, U, A V E, 4}=\left(\dot{q}_{W A L L, C R N 3, U}{ }^{\prime}+\dot{q}_{W A L L, S T P 2, U}\right) / 2 \\
& \dot{q}_{\mathrm{WALL}, \mathrm{L}, \mathrm{AVE}, 4}^{\prime \prime}=\left(\dot{q}_{\mathrm{WALL}, \mathrm{CRN} 3, \mathrm{~L}}+\dot{q}_{\mathrm{WALL}, \mathrm{STP} 2, \mathrm{~L}}\right) / 2 \\
& \dot{q} \dot{W}_{\text {WLL }, U, A V E, 5}=\left(\dot{q}_{\text {WALL,CRN3,U }}^{\prime \prime}+\dot{q}_{W A L L, S T P 3, U}\right) / 2 \\
& \text { qُWALL,L,AVE, } 5=\left(\dot{q}_{W A L L, C R N 3, L}^{\prime \prime}+\dot{q}_{W A L L, S T P 3, L}\right)^{\prime \prime} / 2 \\
& \text { qٔWALL,U,AVE,6 }=\left(\dot{q}_{W A L L, C R N 4, U}^{\prime \prime}+\dot{q}_{W A L L, S T P 3, U}^{\prime \prime}\right) / 2 \\
& \dot{q}{ }_{W A L L, L, A V E, 6}=\left(\dot{q} \text { WALL,CRN4,L }+\dot{q}_{\text {WALL,STP } 3, \mathrm{~L}}\right) / 2 \\
& \dot{q} \ddot{W A L L, U, A V E, 7}=\left(\dot{q}_{W A L L, C R N 4, U} \ddot{m}+\dot{q}_{W A L L, S T P 4, U}\right) / 2
\end{aligned}
$$

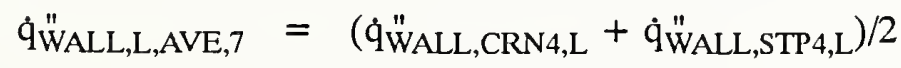

$$
\begin{aligned}
& \dot{q}_{W A L L, U, A V E, 8}=\left(\dot{q}_{W A L L, C R N 1, U}+\dot{q}_{\text {WALL,STP4,U }}\right) / 2 \\
& \dot{q}_{W A L L, L, A V E, 8}^{\prime \prime}=\left(\dot{q}_{\text {WALL,CRN1,L }}^{\prime \prime}+\dot{q}_{\text {WALL,STP } 4, \mathrm{~L}}\right) / 2
\end{aligned}
$$


4. For each of the upper-layer segments use the area of the segment and the previously calculated average $\dot{q}_{\text {WALL }}^{\|}$to calculate the eight contributions to the total rate of upper-layer wall heat transfer. Sum these contributions and obtain finally q'"WALL,U,AVE, the average flux of heat transfer to the upper-layer portions of the walls. Carry out analogous calculations for qैWALL,L,AVE, the average flux of heat transfer to the lower-layer portions of the walls.

Designate the area of upper- and lower-layer wall segment $N$ as $A_{\text {WALL,U,N }}$ and $A_{\text {WALL,L,N }}$, respectively, and calculate these values:

$$
\begin{aligned}
& \mathrm{A}_{\mathrm{WALL}, \mathrm{U}, 1}=\mathrm{A}_{\mathrm{WALL}, \mathrm{U}, 6}=\mathrm{X}_{\mathrm{FIRE}}\left(\mathrm{Z}_{\mathrm{CEIL}}-\mathrm{Z}_{\mathrm{LAYER}}\right) \\
& \mathrm{A}_{\mathrm{WALL}, \mathrm{L}, 1}=\mathrm{A}_{\mathrm{WALL}, \mathrm{L}, 6}=\mathrm{X}_{\mathrm{FIRE}} \mathrm{Z}_{\mathrm{LAYER}} \\
& A_{\mathrm{WALL}, \mathrm{U}, 2}=\mathrm{A}_{\mathrm{WALL}, \mathrm{U}, 5}=\left(\mathrm{X}_{\mathrm{WALL}}-\mathrm{X}_{\mathrm{FIRE}}\right)\left(\mathrm{Z}_{\mathrm{CEIL}}-\mathrm{Z}_{\mathrm{LAYER}}\right) \\
& \mathrm{A}_{\mathrm{WALL}, \mathrm{L}, 2}=\mathrm{A}_{\mathrm{WALL}, \mathrm{L}, 5}=\left(\mathrm{X}_{\mathrm{WALL}}-\mathrm{X}_{\mathrm{FIRE}}\right) \mathrm{Z}_{\mathrm{LAYER}} \\
& A_{\text {WALL }, \text { U } 3}=A_{\text {WALL }, U, 8}=Y_{\text {FIRE }}\left(Z_{\text {CEIL }}-Z_{\text {LAYER }}\right) \\
& A_{\text {WALL }, L, 3}=A_{\text {WALL }, L, 8}=Y_{F I R E} Z_{\text {LAYER }} \\
& A_{\text {WALL }, \text { U, } 4}=A_{\text {WALL }, \text { U, } 7}=\left(Y_{\text {WALL }}-Y_{\text {FIRE }}\right)\left(Z_{\text {CEIL }}-Z_{\text {LAYER }}\right) \\
& A_{\text {WALL }, L, 4}=A_{\text {WALL }, L, 7}=\left(Y_{\text {WALL }}-Y_{\text {FIRE }}\right) Z_{\text {LAYER }}
\end{aligned}
$$

Calculate

$$
\begin{aligned}
& \dot{q}_{W A L L, U, A V E}^{\prime \prime}=\sum_{N=1}^{8}\left(A_{\text {WALL,U,N }} \dot{q}_{W A L L, A V E, U, N}^{\prime \prime}\right) / \sum_{N=1}^{8} A_{\text {WALL,U,N }}
\end{aligned}
$$

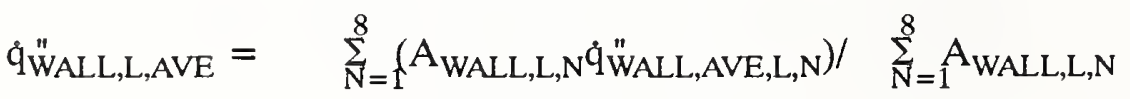

5. Add the rates of heat transfer to all sixteen upper and lower wall segments and obtain, $\mathrm{Q}_{\mathrm{WALL}}$, the total rate of heat transfer to the wall surfaces.

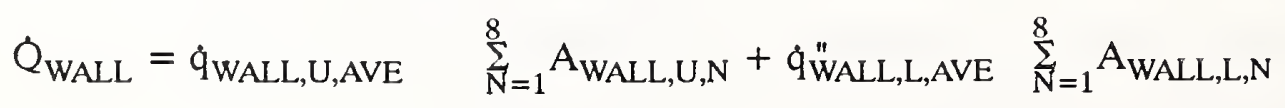


Appendix B: The Subroutine CEILHT for Calculating the Convective Heat Transfer in a Two-Layer Fire Environment From Fire Plume Gases to a Uniform Temperature Ceiling and to Uniform Temperature Walls.

\section{Input and Output Variables}

The CEILHT input and output variables with definitions and units are listed below. Except for EPS, these are taken from the descriptions presented in the body of the text and in Appendix A.

\section{OUTPUT}

$Q_{\text {CEIL }}$

rate of heat transfer to ceiling [W]

$\dot{Q}_{\text {WALL }}$

rate of heat transfer to all wall surfaces [W]

$\dot{q}_{\text {CEIL,AVE }}^{\prime \prime}$

average flux of rate of heat transfer to ceiling $\left[\mathrm{W} / \mathrm{m}^{2}\right]$

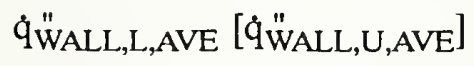

average heat flux to portion of wall in lower [upper] layer $\left[\mathrm{W} / \mathrm{m}^{2}\right]$

$\underline{\text { INPUT }}$

$\dot{\mathrm{M}}_{\text {PLUME }}$

mass flow rate in plume at $Z_{\text {LAYER }}$ if $Z_{\text {FIRE }}<Z_{\text {LAYER }}[\mathrm{kg} / \mathrm{s}]$

$\dot{Q}_{\text {FCONV }}$

portion of fire energy release rate convected in plume [W] 
$\mathrm{T}_{\text {CEIL }}$

average temperature of ceiling $[\mathrm{K}]$

$\mathrm{T}_{\mathrm{L}}, \mathrm{T}_{\mathrm{U}}$

temperature of lower [upper] layer $[\mathrm{K}]$

$T_{\text {WALL }}$

average temperature of the wall surfaces $[\mathrm{K}]$

$\mathrm{X}_{\text {WALL }}, \mathrm{Y}_{\mathrm{WALL}}$, and $\mathrm{Z}_{\mathrm{CEIL}}$

$\mathrm{X}, \mathrm{Y}, \mathrm{Z}$ of room corner diagonal from origin [m]

$\mathrm{X}_{\mathrm{FIRE}}, \mathrm{Y}_{\mathrm{FIRE}}$, and $\mathrm{Z}_{\mathrm{FIRE}}$

$\mathrm{X}, \mathrm{Y}, \mathrm{Z}$ of center of base of fire [m]

$Z_{\text {LAYER }}$

$\mathrm{Z}$ of layer interface $[\mathrm{m}]$

$\rho_{\mathrm{L}}, \rho_{\mathrm{U}}$

density of lower [upper] layer $\left[\mathrm{kg} / \mathrm{m}^{3}\right.$ ]

Cross-Reference Between Nomenclature and Subroutine Variables

Below is a cross-reference between variables defined in the Nomenclature section and variables used in the subroutine.

\section{NOMENCLATURE VARIABLES SUBROUTINE VARIABLES}
$\mathrm{A}_{\mathrm{WALL}, \mathrm{L}, \mathrm{N}}, \mathrm{A}_{\mathrm{WALL}, \mathrm{U}, \mathrm{N}}$
$\operatorname{AWU}(\mathrm{N}), \operatorname{AWU}(\mathrm{N})\left[\mathrm{m}^{2}\right]$
$\mathrm{C}_{\mathrm{p}}$
$\mathrm{CP}$ (use 1000.) [Ws/(kg.K)] 
$\mathrm{C}_{\mathrm{T}}$

$\mathrm{f}(\mathrm{r} / \mathrm{H})$

g

$\mathrm{H}$

ก

$\mathrm{h}_{\mathrm{L}}$

$\mathrm{h}_{\mathrm{ST}}$

M*

$\dot{M}_{\text {PLUME }}$

Pr

Q'

$Q_{\text {CEIL }}$

$\mathrm{Q}_{\mathrm{EQ}}^{*}$

$\mathrm{Q}_{\mathrm{H}}^{*}$

$\mathrm{Q}_{\text {FCONV }}$

$Q_{\text {PLUME }}$

QWALL

$\mathfrak{q}_{\text {CEIL }}^{\prime \prime}$

q̊CEIL,AVE

q̊̈WLL

q̊ẄALL,CRNN,L, $\dot{\text { qWALL,CRNN,U }}$

q̊WALL,L,AVE, q̊WALL,U,AVE

q̊WALL,L,AVE,N,${ }_{\text {WALL,U,AVE,N }}$

q̊WALL,NORM,L,
CT (use 9.115)

F

$\mathrm{G}$ (use 9.8$)\left[\mathrm{m} / \mathrm{s}^{2}\right]$

$\mathrm{H}[\mathrm{m}]$

$\mathrm{HTCT}\left[\mathrm{W} /\left(\mathrm{m}^{2} \cdot \mathrm{K}\right)\right]$

HTCL $\left[\mathrm{W} /\left(\mathrm{m}^{2} \cdot \mathrm{K}\right)\right]$

$\operatorname{HTCST}\left[\mathrm{W} /\left(\mathrm{m}^{2} \cdot \mathrm{K}\right)\right]$

MFRAC

MPLUME [m/s]

PR

QCONT [W]

QCEIL [W]

QEQ [W]

$\mathrm{QH}$

QCONV [W]

QPLUME [W]

QWALL [W]

QFCLG $\left[\mathrm{W} / \mathrm{m}^{2}\right]$

QFCLGA $\left[\mathrm{W} / \mathrm{m}^{2}\right]$

$\mathrm{QFW}\left[\mathrm{W} / \mathrm{m}^{2}\right]$

QFWCL(N), QFWCU(N) $\left[\mathrm{W} / \mathrm{m}^{2}\right]$

QFWLA, QFWUA [W/m²]

QFWLAN(N), QFWUAN(N) $\left[\mathrm{W} / \mathrm{m}^{2}\right]$

QFWNL, QFWNU [W/m $\left.\mathrm{m}^{2}\right]$ 
qै"WALL,ST

q̊"wALL,STPN,L, qُ"WALL,STPN,U

$\mathrm{Re}_{\mathrm{H}}$

r

${ }^{\mathrm{r}} \mathrm{CRNN}$

$\mathrm{r}_{\mathrm{ST}}$

$\mathrm{r}_{\text {STPN }}$

$\mathrm{T}_{\mathrm{AD}}$

$\mathrm{T}_{\text {CEIL }}$

$\mathrm{T}_{\mathrm{CJ}}$

$\mathrm{T}_{\mathrm{L}}, \mathrm{T}_{\mathrm{U}}$

$\mathrm{T}_{\text {WALL }}$

V

$\mathrm{V}_{\mathrm{CJ}}$

$\mathrm{V}_{\text {MAX }}$

$\mathrm{X}, \mathrm{Y}, \mathrm{Z}$

$\mathrm{X}_{\text {WALL }}, \mathrm{Y}_{\mathrm{WALL}}$, and $\mathrm{Z}_{\mathrm{CEIL}}$

$\mathrm{X}_{\text {FIRE }}, \mathrm{Y}_{\text {FIRE }}$, and $\mathrm{Z}_{\text {FIRE }}$

$\mathrm{Z}_{\mathrm{EQ}}$

$\mathrm{Z}_{\text {LAYER }}$

$\mathrm{Z}_{\text {SOURCE }}$

Z

$\alpha$

$\delta$
QFWST $\left[\mathrm{W} / \mathrm{m}^{2}\right]$

QFWSL(N), QFWSU(N) $\left[\mathrm{W} / \mathrm{m}^{2}\right]$

RE

$\mathrm{R}$ [m]

$\mathrm{RC}(\mathrm{N})[\mathrm{m}]$

RST [m]

$\mathrm{RS}(\mathrm{N})[\mathrm{m}]$

$\mathrm{TAD}[\mathrm{K}]$

$\mathrm{TC}[\mathrm{K}]$

$\mathrm{TCJ}[\mathrm{K}]$

$\mathrm{TL}, \mathrm{TU}[\mathrm{K}]$

TW [K]

$\mathrm{VCH}[\mathrm{m} / \mathrm{s}]$

$\mathrm{VCJ}[\mathrm{m} / \mathrm{s}]$

$\mathrm{VMAX}[\mathrm{m} / \mathrm{s}]$

$\mathrm{X}, \mathrm{Y}, \mathrm{Z}$ [m]

$\mathrm{XW}, \mathrm{YW}, \mathrm{ZC}[\mathrm{m}]$

$\mathrm{XF}, \mathrm{YF}, \mathrm{ZF}[\mathrm{m}]$

ZEQ [m]

ZLAY [m]

ZS [m]

$\mathrm{Z}$ [m]

ALPHA

DEL [m] 
$\Theta$

$\Theta_{\mathrm{S}}$

$\lambda_{\mathrm{CONV}}$

$v_{U}$

$\rho_{\mathrm{L}}, \rho_{\mathrm{U}}$

$\sigma$
THETA

THETAS

LAMC

ANU $\left[\mathrm{m}^{2} / \mathrm{s}\right]$

RHOL, RHOU $\left[\mathrm{kg} / \mathrm{m}^{3}\right]$

SIGMA

The Subroutine CEILHT

On the following pages is a listing of the subroutine CEILHT. 


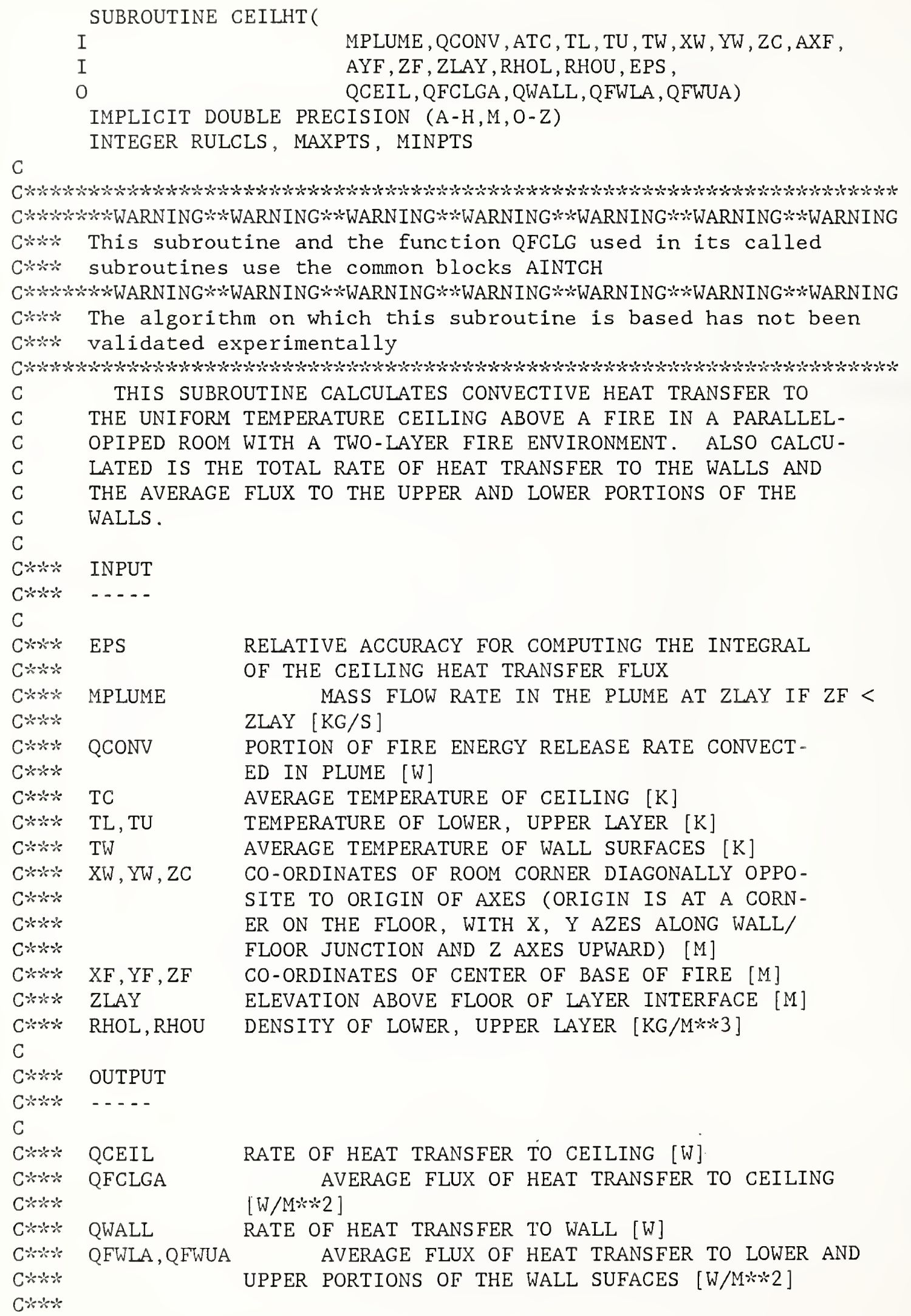




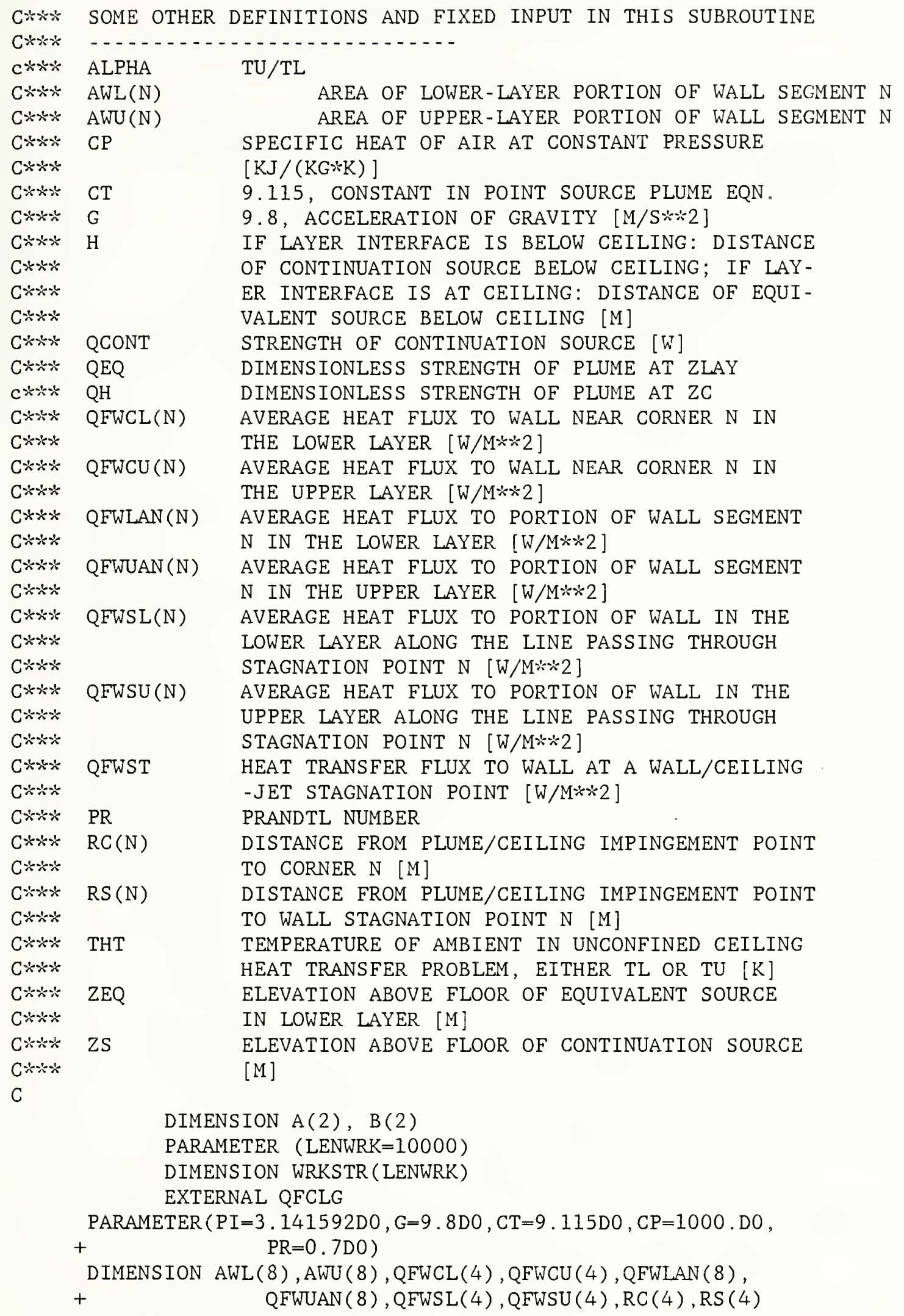


COMMON/AINTCH/H, HTCT , THT, THTQHP , C1 , C2 , C3 , XF , YF , TC

$\mathrm{XF}=\mathrm{AXF}$

$\mathrm{YF}=\mathrm{AYF}$

$\mathrm{TC}=\mathrm{ATC}$

IF (ZF. LT.ZLAY) THEN

C

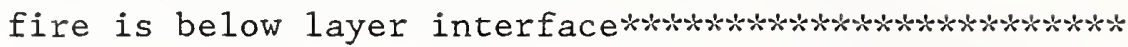
$\mathrm{QEQ}=(0.21 \mathrm{D} 0 * \mathrm{QCONV} /(\mathrm{CP} * \mathrm{TL} * \mathrm{MPLUME})) * *(3 . \mathrm{D} 0 / 2 . \mathrm{D} 0)$ $\mathrm{ZEQ}=\mathrm{ZLAY}-(\mathrm{QCONV} /(\mathrm{QEQ} * \mathrm{RHOL} * \mathrm{CP} * \mathrm{TL} * \mathrm{DSQRT}(\mathrm{G}))) * *$

$+$

IF (ZLAY.LT.ZC) THEN

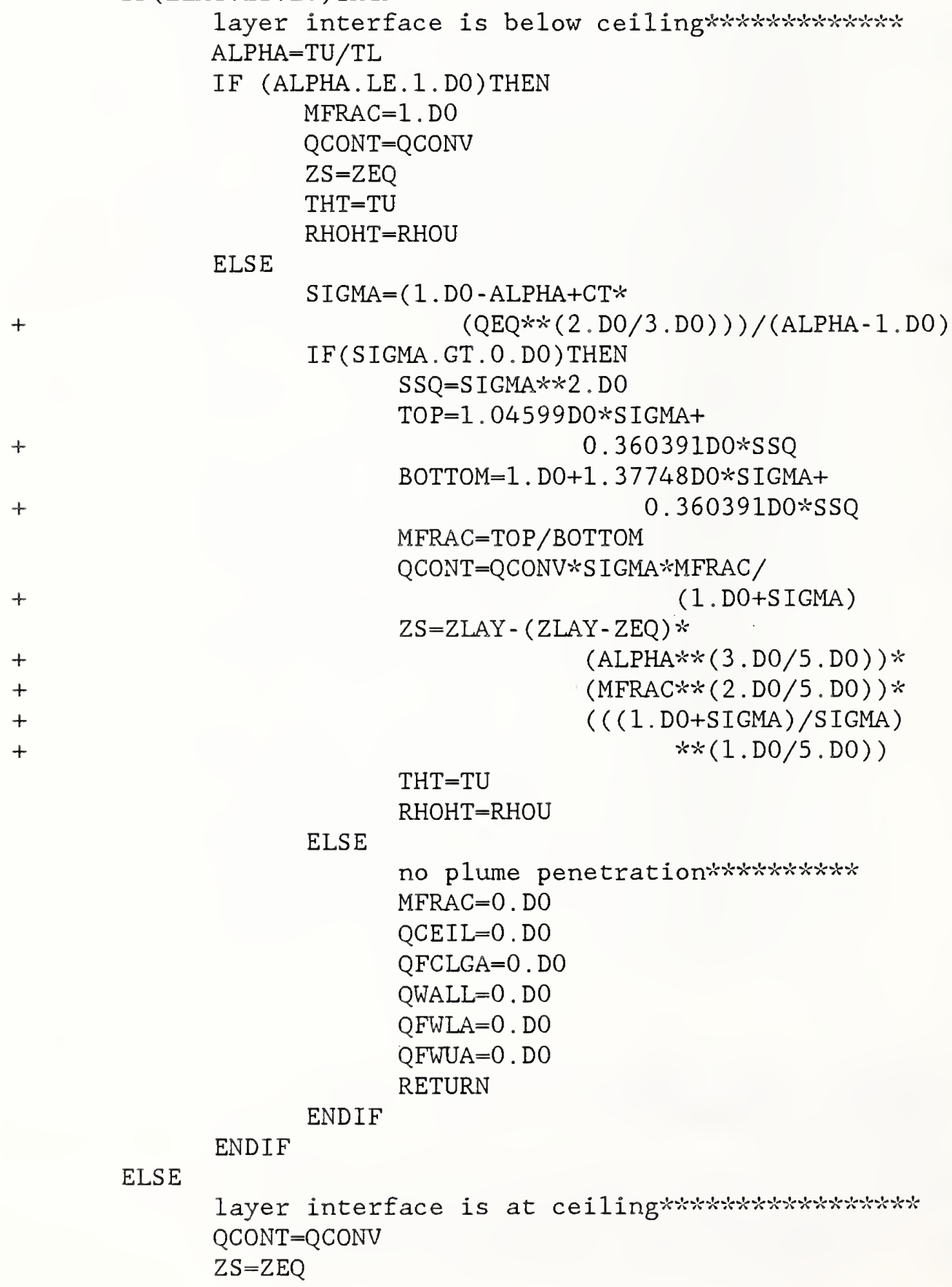

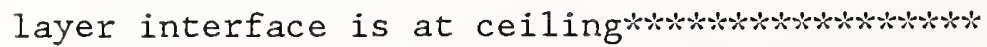
$\mathrm{QCONT}=\mathrm{QCONV}$

$\mathrm{ZS}=\mathrm{ZEQ}$ 


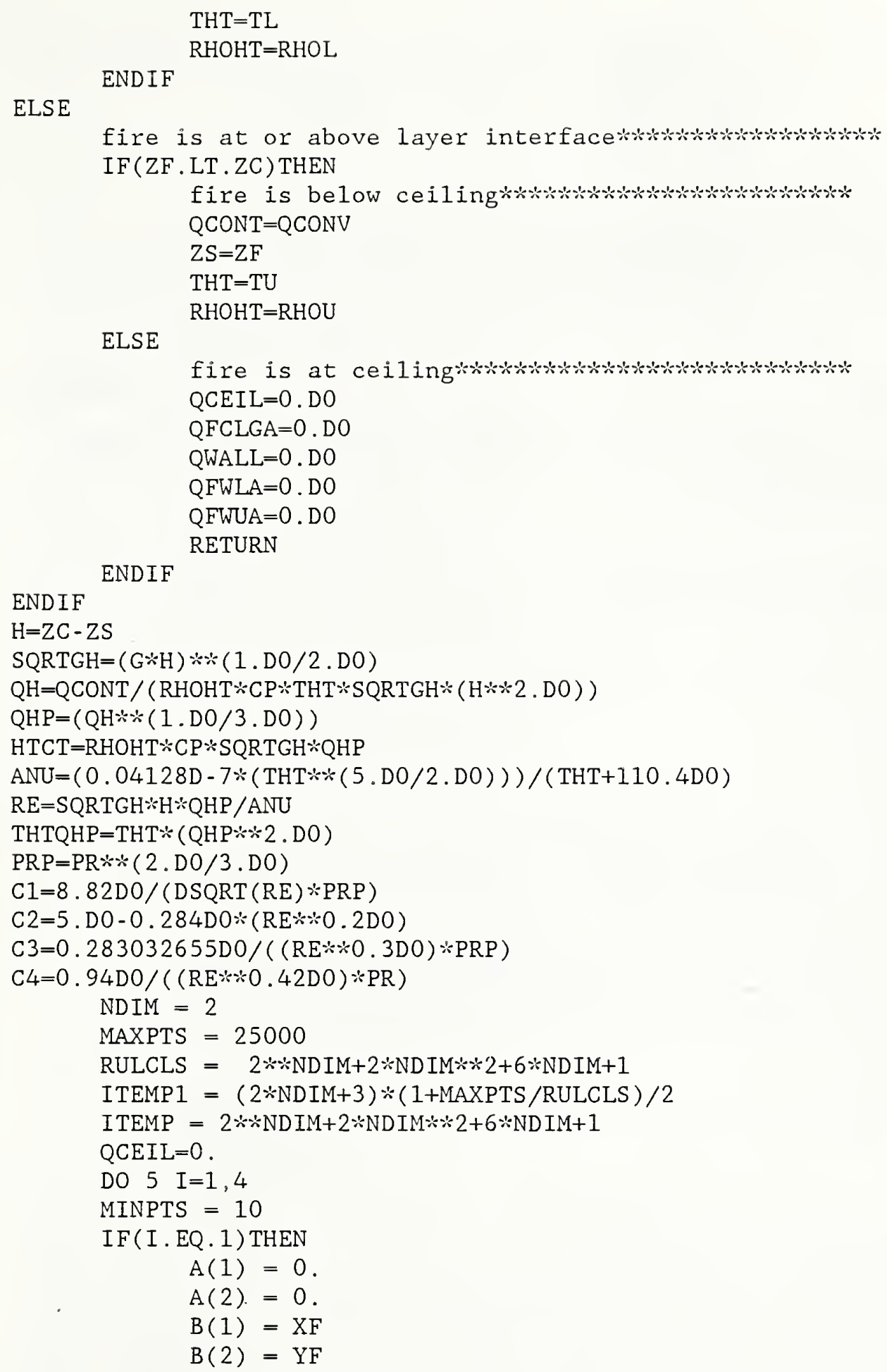

ELSE

IF ( I.EQ. 2) THEN

$$
\begin{aligned}
& A(1)=X F \\
& A(2)=0 . \\
& B(1)=X W
\end{aligned}
$$


ELSE

$B(2)=Y F$

IF ( I . EQ . 3) THEN

$$
\begin{aligned}
& A(1)=X F \\
& A(2)=Y F \\
& B(1)=X W \\
& B(2)=Y W
\end{aligned}
$$

ELSE

ENDIF

ENDIF

$$
\begin{aligned}
& A(1)=0 . \\
& A(2)=Y F \\
& B(1)=X F \\
& B(2)=Y W
\end{aligned}
$$

ENDIF

CALL ADAPT (NDIM, A, B, MINPTS , MAXPTS , QFCLG, EPS , RELERR, LENWRK,

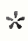
WRKSTR, ADDQCEIL, IFAIL)

5 QCEIL $=$ QCEIL+ADDQCEIL

CONTINUE

IF(IFAIL.GT.0) QCEIL=0.DO

QFCLGA $=$ QCEIL/ $(X W * Y W)$

C****

$\mathrm{C} * \dot{x} * \dot{x}$

C****

Now calculate wall heat transfer:

Step 1 .

Calculate radii at wall stagnation points:

$\mathrm{RS}(1)=\mathrm{YF}$

$\mathrm{RS}(2)=\mathrm{XW}-\mathrm{XF}$

$\operatorname{RS}(3)=Y W-Y F$

$\operatorname{RS}(4)=X F$

$\operatorname{RMIN}=\operatorname{MIN}(\operatorname{RS}(1), \operatorname{RS}(2), \operatorname{RS}(3), \operatorname{RS}(4))$

IF (RMIN.LT .0.2*(ZC-ZF)) THEN

WRITE $(6, *)^{\prime}$ IMPINGEMENT POINT IS CLOSER TO A WALL THAN 0.2 OF ',

+ 'FIRE-TO-CEILING DISTANCE'

ENDIF

C*i*: Calculate average heat transfer fluxes to lower and upper

Cris: walls along the vertical lines passing through the four wall/

C*** ceiling-jet stagnation points:

DO $10 \mathrm{~N}=1,4$

$\mathrm{RDH}=\mathrm{RS}(\mathrm{N}) / \mathrm{H}$

CALL SQFWST (RDH, H , C4, THT , HTCT, THTQHP, TW, QFWSL(N), QFWSU(N),

$$
+
$$

10 ZC, ZLAY)

Cris: Step 2.

C**** Calculate radii at room corners:

$\mathrm{RC}(1)=\mathrm{DSQRT}(\mathrm{XF} * \div 2$. DO+YF $* 2 . \mathrm{DO})$

$\mathrm{RC}(2)=\mathrm{DSQRT}((\mathrm{XW}-\mathrm{XF}) * * 2 . \mathrm{DO}+\mathrm{YF} * * 2 . \mathrm{DO})$

$\mathrm{RC}(3)=\mathrm{DSQRT}((\mathrm{XW}-\mathrm{XF}) * * 2 . \mathrm{D} 0+(\mathrm{YW}-\mathrm{YF}) * * 2 . \mathrm{DO})$

$\mathrm{RC}(4)=\mathrm{DSQRT}(\mathrm{XF} * * 2 . \mathrm{D} 0+(\mathrm{YW}-\mathrm{YF}) * \div 2 . \mathrm{DO})$

C*:*: Calculate average heat transfer fluxes to lower and upper

C*r: walls along the vertical lines passing through the four room C*:* corners by assuming that the heat transfer there is as along C**: a line passing through a point of normal ceiling-jet/wall imC***\% pingement. 
DO $20 \mathrm{~N}=1,4$

$\mathrm{RDH}=\mathrm{RC}(\mathrm{N}) / \mathrm{H}$

CALL SQFWST (RDH , H , C4, THT , HTCT , THTQHP, TW, QFWCL(N), QFWCU(N), $+$

CONTINUE

ZC, ZLAY)

Ciriti Step 3 .

C*** Calculate the average heat transfer fluxes to the lower and C*ix upper portions of the eight wall segments bounded by the room Crix corners and the the vertical lines passing through the points C*i* of normal wall/ceiling-jet impingement.

QFWUAN (1) $=($ QFWCU (1) +QFWSU (1) $) / 2$. DO

QFWLAN $(1)=($ QFWCL $(1)+$ QFWSL $(1)) / 2$.DO

$\operatorname{QFWUAN}(2)=(\operatorname{QFWCU}(2)+\mathrm{QFWSU}(1)) / 2$.DO

QFWLAN (2) $=(\operatorname{QFWCL}(2)+\mathrm{QFWSL}(1)) / 2$. DO

QFWUAN (3) $=(\operatorname{QFWCU}(2)+\mathrm{QFWSU}(2)) / 2$.DO

QFWLAN (3) $=($ QFWCL (2) +QFWSL (2) ) $/ 2$. DO

QFWUAN (4) $=(\operatorname{QFWCU}(3)+\mathrm{QFWSU}(2)) / 2$. DO

QFWLAN (4) $=($ QFWCL (3) +QFWSL (2) $) / 2$. DO

QFWUAN $(5)=(\operatorname{QFWCU}(3)+\mathrm{QFWSU}(3)) / 2$. DO

QFWLAN ( 5) $=($ QFWCL (3) + QFWSL (3) $) / 2$. DO

QFWUAN $(6)=($ QFWCU (4) + QFWSU (3) $) / 2$. DO

QFWLAN (6) $=($ QFWCL (4) + QFWSL (3) $) / 2$. DO

QFWUAN ( 7) $=($ QFWCU (4) +QFWSU (4) ) $/ 2$. DO

QFWLAN $(7)=($ QFWCL $(4)+$ QFWSL $(4)) / 2$. DO

QFWUAN (8) $=($ QFWCU (1) +QFWSU (4) ) $/ 2$. DO

C*** QFWLAN (8) $=($ QFWCL $(1)+$ QFWSL (4) $) / 2$. DO

Step 4.

C*** For each of the upper layer segments use the area of the seg$C \times *$ ment and the previously calculated average heat transfer

C*** flux to calculate the eight contributions to theto the total C*i* rate of upper-layer wall heat transfer. Sum these contribu$C * * x$ tions and obtain finally the average rate of heat transfer to C*** the upper-layer portions of the walls. Carry out analogous $C * * *$ calculations for the lower wall surfaces. Add rates of heat C*** transfer to all 16 wall surface segments and obtain total

C***: rate of heat transfer to the wall.

$A W L(1)=X F * Z L A Y$

$\operatorname{AWU}(1)=\mathrm{XF} *(Z \mathrm{C}-\mathrm{ZLAY})$

$A W L(2)=(X W-X F) * Z L A Y$

AWU $(2)=(X W-X F) *(Z C-Z L A Y)$

AWL $(3)=Y F * Z L A Y$

$\operatorname{AWU}(3)=Y F *(Z C-Z L A Y)$

$A W L(4)=(Y W-Y F) * Z I A Y$

$\operatorname{AIUU}(4)=(Y W-Y F) *(Z C-Z L A Y)$

$A W L(5)=A W L(2)$

AWU $(5)=$ AWU $(2)$

$\mathrm{AWL}(6)=\mathrm{AWL}(1)$

$\operatorname{AWU}(6)=\operatorname{AWU}(1)$

$\operatorname{AWL}(7)=\operatorname{AWL}(4)$

AWU (7) $=$ AWU (4)

$\operatorname{AWL}(8)=A W L(3)$ 


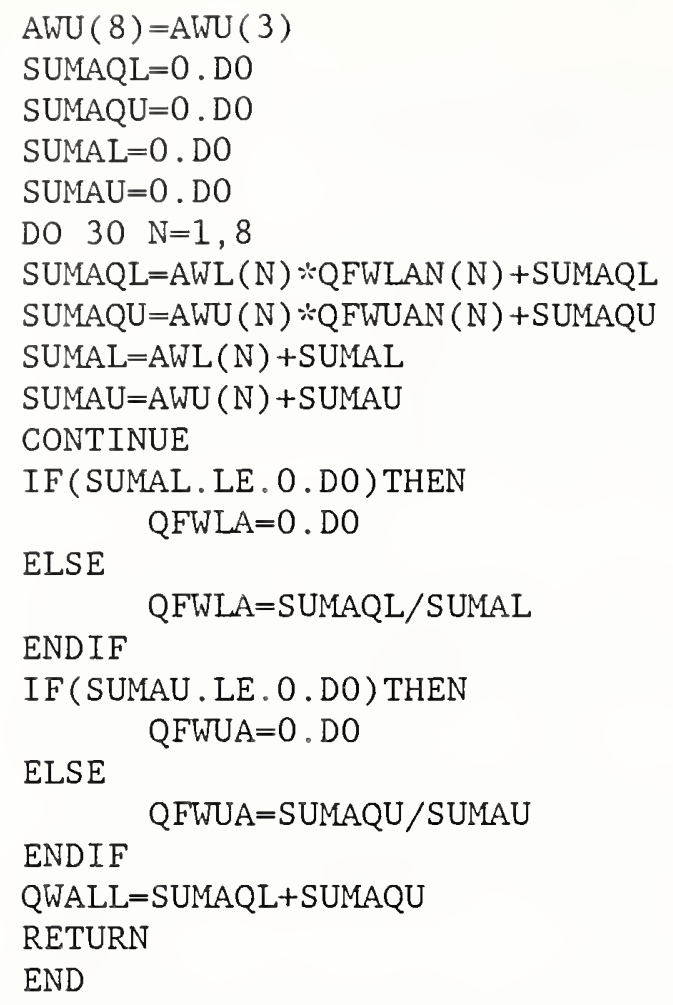

C

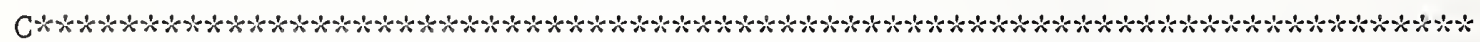

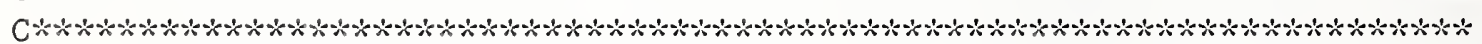
SUBROUTINE SQFWST (RDH, H, C4, THT, HTCT, THTQHP, TW, QFWLOW, QFWUP, $+\quad$ ZC, ZLAY)

C*:* Calculate average heat transfer fluxes to lower and upper

C*r: walls along a vertical line passing through a wall/ceilingC*** jet stagnation point IMPLICIT DOUBLE PRECISION (A-H, M,O-Z)

$\mathrm{F}=(1 . \mathrm{DO}-1.1 \mathrm{DO} *(\mathrm{RDH} * * 0.8 \mathrm{DO})+0.808 \mathrm{D} 0 *(\mathrm{RDH} * * 1.6 \mathrm{DO})) /$

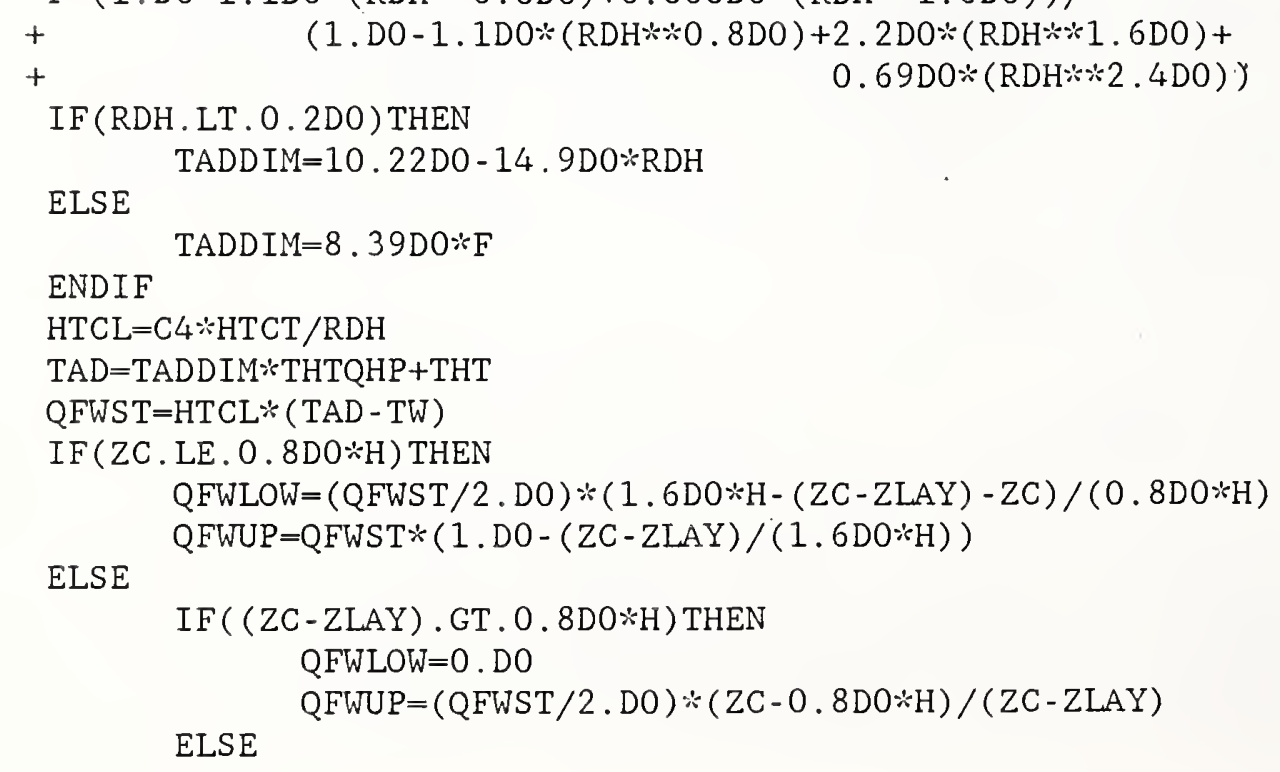


ENDIF ENDIF

QFWLOW $=($ QFWST $/ 2 . D 0) *(0.8 D 0 * \mathrm{H}-($ ZC - ZLAY $)) /$ ZLAY

QFWUP $=$ QFWST $*(1 . D 0-(2 \mathrm{C}-\mathrm{ZLAY}) /(1.6 \mathrm{D} 0 * \mathrm{H}))$

RETURN

END

C*

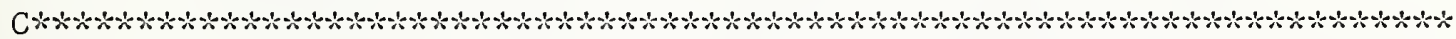

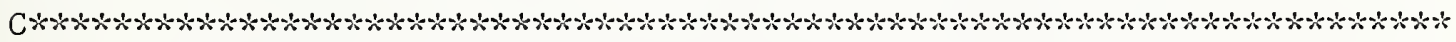

SUBROUTINE ADAPT (NDIM , A, B , MINPTS , MAXPTS , FUNCTN , EPS , RELERR, LENWRK, $*$ WRKSTR, FINEST , IFAIL)

IMPLICIT DOUBLE PRECISION (A-H,O-Z)

C***:BEGIN PROLOGUE ADAPT

C ADAPTIVE MULTIDIMENSIONAL INTEGRATION SUBROUTINE

C

AUTHOR: A. C. GENZ, Washington State University

19 March 1984

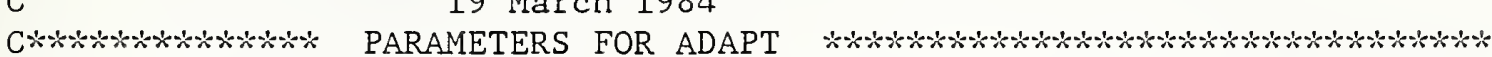

C****** INPUT PARAMETERS

C NDIM NUMBER OF VARIABLES, MUST EXCEED 1, BUT NOT EXCEED 20

C A REAL ARRAY OF LOWER LIMITS, WITH DIMENSION NDIM

C B REAL ARRAY OF UPPER LIMITS, WITH DIMENSION NDIM

C MINPTS MINIMUM NUMBER OF FUNCTION EVALUATIONS TO BE ALLOWED.

C ON THE FIRST CALL TO ADAPT MINPTS SHOULD BE SET TO A

C

NON NEGATIVE VALUE. (CAUTION... MINPTS IS ALTERED BY ADAPT)

IT IS POSSIBLE TO CONTINUE A CALCULATION TO GREATER ACCURACY

BY CALLING ADAPT AGAIN BY DECREASING EPS (DESCRIBED BELOW)

AND RESETTING MINPTS TO ANY NEGATIVE VALUE.

MINPTS MUST NOT EXCEED MAXPTS.

MAXPTS MAXIMUM NUMBER OF FUNCTION EVALUATIONS TO BE ALLOWED,

WHICH MUST BE AT LEAST RULCLS, WHERE

RULCLS $=2 * *$ NDIM+2*NDIM**2+6*NDIM+1

FOR NDIM $=\begin{array}{lllllllll}2 & 3 & 4 & 5 & 6 & 7 & 8 & 9 & 10\end{array}$

MAXPTS >= $\begin{array}{llllllllll}25 & 45 & 73 & 113 & 173 & 269 & 433 & 729 & 1285\end{array}$

A suggested value for MAXPTS is 100 times the above values.

FUNCTN EXTERNALLY DECLARED USER DEFINED FUNCTION TO BE INTEGRATED.

IT MUST HAVE PARAMETERS (NDIM,Z), WHERE Z IS A REAL ARRAY

OF DIMENSION NDIM.

EPS REQUIRED RELATIVE ACCURACY

LENWRK LENGTH OF ARRAY WRKSTR OF WORKING STORAGE, THE ROUTINE

NEEDS $(2 *$ NDIM+3)*(1+MAXPTS/RULCLS $) / 2$ FOR LENWRK IF

MAXPTS FUNCTION CALLS ARE USED.

FOR GUIDANCE, IF YOU SET MAXPTS TO 100*RULCLS (SEE TABLE

ABOVE) THEN ACCEPTABLE VALUES FOR LENWRK ARE

$\begin{array}{lccccccll}\text { FOR NDIM }= & 2 & 3 & 4 & 5 & 6 & 7 & 8 & 9 \\ \text { LENWRK }= & 357 & 561 & 1785 & 3417 & 6681 & 13209 & 26265 & 52377\end{array}$

C

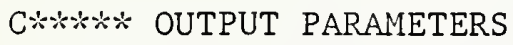

C MINPTS ACTUAL NUMBER OF FUNCTION EVALUATIONS USED BY ADAPT

C WRKSTR REAL ARRAY OF WORKING STORAGE OF DIMENSION (LENWRK). 


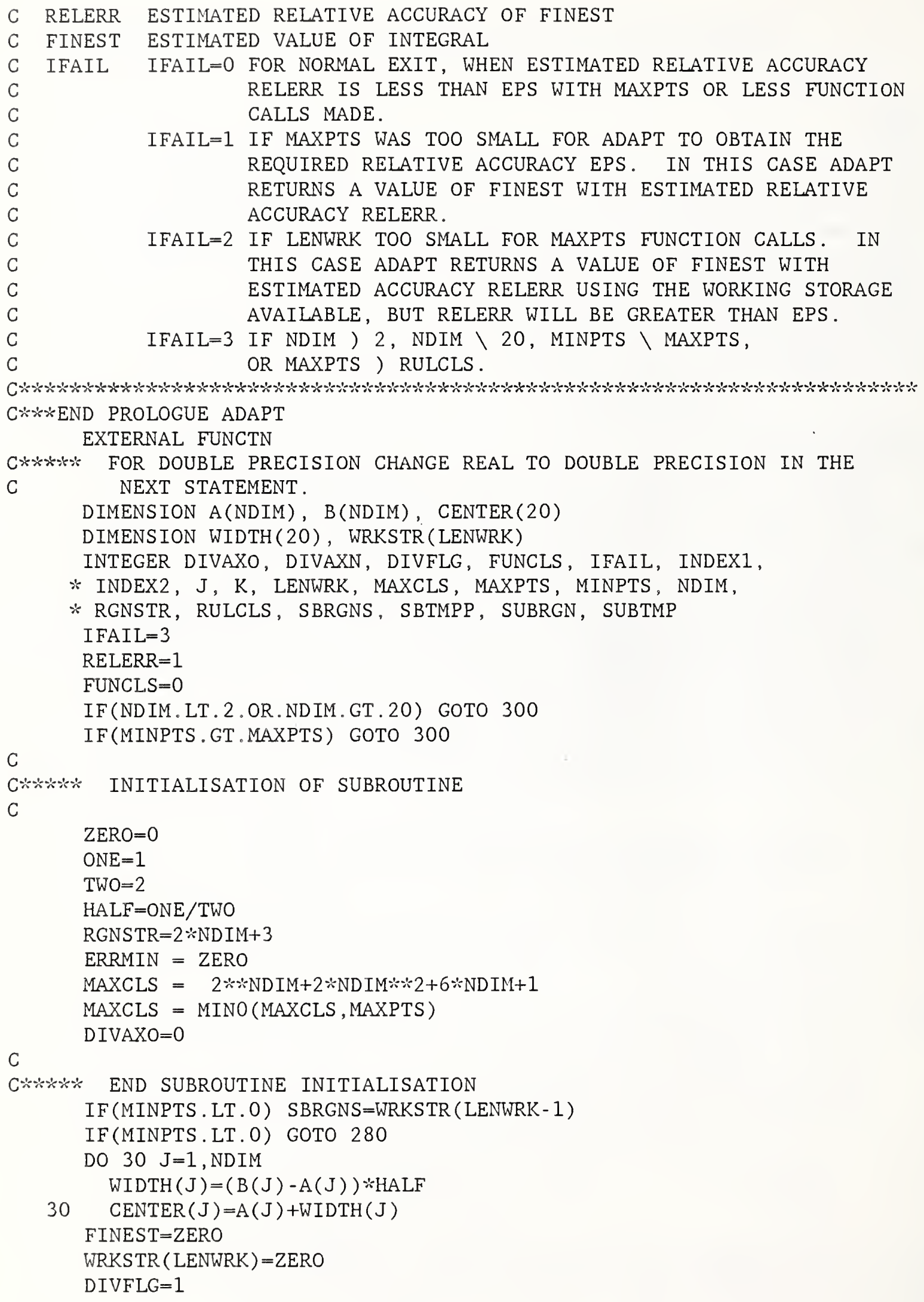


SUBRGN=RGNSTR

$S B R G N S=R G N S T R$

40 CALL BSRL(NDIM, CENTER, WIDTH, FUNCTN, MAXCLS, RULCLS,

* ERRMIN , RGNERR, RGNVAL, DIVAXO, DIVAXN)

FINEST=FINEST+RGNVAL

WRKSTR $($ LENWRK) $=$ WRKSTR $($ LENWRK $)+$ RGNERR

FUNCLS $=$ FUNCLS + RULCLS

C

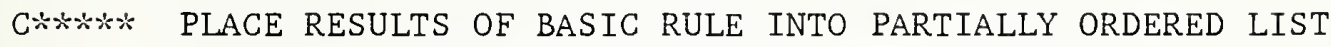

C***** ACCORDING TO SUBREGION ERROR

IF(DIVFLG.EQ.1) GO TO 230

C

Cr*x*r: WHEN DIVFLG=0 START AT TOP OF LIST AND MOVE DOWN LIST TREE TO

C FIND CORRECT POSITION FOR RESULTS FROM FIRST HALF OF RECENTLY

C DIVIDED SUBREGION

200 SUBTMP $=2 \div$ SUBRGN

IF (SUBTMP.GT.SBRGNS) GO TO 250

IF (SUBTMP.EQ.SBRGNS) GO TO 210

$S B T M P P=S U B T M P+R G N S T R$

IF (WRKSTR (SUBTMP) . LT . WRKSTR (SBTMPP)) SUBTMP=SBTMPP

210 IF(RGNERR.GE.WRKSTR(SUBTMP)) GO TO 250

DO $220 \mathrm{~K}=1$, RGNSTR

INDEX $1=$ SUBRGN $-\mathrm{K}+1$

INDEX $2=$ SUBTMP $-\mathrm{K}+1$

220 WRKSTR (INDEX1) =WRKSTR ( INDEX2)

SUBRGN=SUBTMP

GOTO 200

C

C

C TREE TO FIND CORRECT POSITION FOR RESULTS FROM SECOND HALF OF

C RECENTLY DIVIDED SUBREGION

230 SUBTMP $=($ SUBRGN $/($ RGNSTR $* 2)) *$ RGNSTR

IF (SUBTMP. LT.RGNSTR) GO TO 250

IF (RGNERR. LE.WRKSTR(SUBTMP)) GO TO 250

DO $240 \mathrm{~K}=1$, RGNSTR

INDEXI $=$ SUBRGN $-\mathrm{K}+1$

INDEX $2=$ SUBTMP $-\mathrm{K}+1$

240 WRKSTR (INDEX1) =WRKSTR (INDEX2)

SUBRGN=SUBTMP

GOTO 230

C****** STORE RESULTS OF BASIC RULE IN CORRECT POSITION IN LIST

250 WRKSTR (SUBRGN) $=$ RGNERR

WRKSTR ( SUBRGN - 1) $=$ RGNVAL

WRKSTR ( SUBRGN - 2) =DIVAXN

DO $260 \mathrm{~J}=1$, NDIM

SUBTMP $=$ SUBRGN $-2 *(\mathrm{~J}+1)$

WRKSTR $(\operatorname{SUBTMP}+1)=\operatorname{CENTER}(\mathrm{J})$

260 WRKSTR ( SUBTMP) $=$ WIDTH $(\mathrm{J})$

IF(DIVFLG.EQ.1) GO TO 270

C*r\% WHEN DIVFLG=0 PREPARE FOR SECOND APPLICATION OF BASIC RULE CENTER $($ DIVAXO $)=$ CENTER $($ DIVAXO $)+$ TWO $*$ WIDTH $($ DIVAXO $)$

$S B R G N S=S B R G N S+R G N S T R$ 
SUBRGN $=$ SBRGNS

DIVFLG $=1$

Cwr子iri LOOP BACK TO APPLY BASIC RULE TO OTHER HALF OF SUBREGION

GO TO 40

C

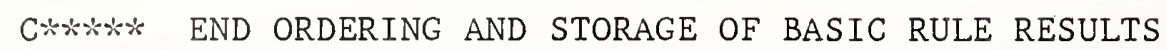

Crが火火 MAKE CHECKS FOR POSSIBLE TERMINATION OF ROUTINE

C

C※ッ゙ FOR DOUBLE PRECISION CHANGE ABS TO DABS IN THE NEXT STATEMENT

270 RELERR=ONE

IF (WRKSTR (LENWRK) . LE . ZERO) WRKSTR (LENWRK) =ZERO

IF (ABS (FINEST) . NE. ZERO) RELERR=WRKSTR (LENWRK) /ABS (FINEST)

IF (RELERR. GT. ONE) RELERR=ONE

IF (SBRGNS+RGNSTR. GT . LENWRK - 2) IFAIL $=2$

IF (FUNCLS+FUNCLS*RGNSTR/SBRGNS.GT.MAXPTS) IFAIL $=1$

IF (RELERR. LT . EPS . AND . FUNCLS . GE . MINPTS) IFAIL $=0$

$\mathrm{C}$

IF(IFAIL.LT.3) GOTO 300

C*r*゙* PREPARE TO USE BASIC RULE ON EACH HALF OF SUBREGION WITH LARGEST

C ERROR

280 DIVFLG $=0$

SUBRGN=RGNSTR

SUBTMP $=2 *$ SBRGNS $/$ RGNSTR

MAXCLS $=$ MAXPTS $/$ SUBTMP

ERRMIN $=$ ABS $($ FINEST $) *$ EPS $/$ FLOAT $($ SUBTMP $)$

WRKSTR (LENWRK) $=$ WRKSTR (LENWRK) - WRKSTR (SUBRGN)

FINEST=FINEST - WRKSTR (SUBRGN - 1)

DIVAXO $=$ WRKSTR $($ SUBRGN -2$)$

DO $290 \mathrm{~J}=1$, NDIM

SUBTMP $=$ SUBRGN $-2 *(\mathrm{~J}+1)$

$\operatorname{CENTER}(\mathrm{J})=\operatorname{WRKSTR}(\operatorname{SUBTMP}+1)$

$290 \operatorname{WIDTH}(\mathrm{J})=$ WRKSTR (SUBTMP)

WIDTH (DIVAXO) $=$ WIDTH (DIVAXO) *HALF

C

CENTER $($ DIVAXO $)=$ CENTER $($ DIVAXO $)-$ WIDTH $($ DIVAXO $)$

C***** LOOP BACK TO APPLY BASIC RULE

C

GOTO 40

C

C***: TERMINATION POINT

C

300 MINPTS $=$ FUNCLS

WRKSTR $($ LENWRK -1$)=$ SBRGNS

RETURN

END

C** C

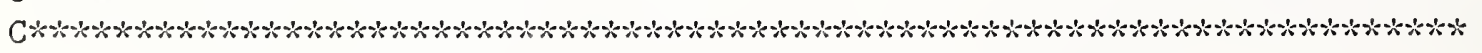
SUBROUTINE BSRL(S, CENTER, HWIDTH, F, MAXVLS, FUNCLS, * $\quad$ ERRMIN, ERREST, BASEST, DIVAXO, DIVAXN)

IMPLICIT DOUBLE PRECISION ( $\mathrm{A}-\mathrm{H}, \mathrm{O}-\mathrm{Z}$ )

EXTERNAL $F$ 
INTEGER S, DIVAXN, DIVAXO, FUNCLS, INTCLS, I, MINDEG, MAXDEG, * MAXORD, MINORD, MAXCLS

DOUBLE PRECISION INTVLS

DIMENSION CENTER(S), HWIDTH(S)

DIMENSION INTVLS (20), Z(20), FULSMS (200), WEGHTS (200)

MAXDEG $=12$

MINDEG $=4$

MINORD $=0$

$\mathrm{ZERO}=0$

$\mathrm{ONE}=1$

TWO $=2$

THREE $=3$

FIVE $=5$

$\mathrm{TEN}=10$

DO 10 MAXORD = MINDEG, MAXDEG

CALL SYMRL(S, CENTER, HWIDTH, F, MINORD, MAXORD, INTVLS,

* INTCLS, 200, WEGHTS, FULSMS, IFAIL)

IF (IFAIL.EQ.2) GOTO 20

ERREST $=$ ABS $($ INTVLS (MAXORD) - INTVLS (MAXORD - I))

ERRORM $=$ ABS (INTVLS (MAXORD - 1$)-\operatorname{INTVLS~(MAXORD-2))~}$

IF (ERREST.NE. ZERO)

$*$ ERREST = ERREST*AMAX1 (ONE/TEN, ERREST/AMAX1 (ERREST/TWO, ERRORM))

IF (ERRORM.LE.FIVE*ERREST) GOTO 20

IF $(2 *$ INTCLS.GT.MAXVLS $)$ GOTO 20

IF (ERREST.LT.ERRMIN) GOTO 20

10 CONTINUE

20 DIFMAX $=-1$

$\mathrm{X} 1=\mathrm{ONE} / \mathrm{TWO} * * 2$

$\mathrm{X} 2=\mathrm{THREE} * \mathrm{X} 1$

DO $30 \quad I=1, S$

$\mathrm{Z}(\mathrm{I})=\operatorname{CENTER}(\mathrm{I})$

30 CONTINUE

SUMO $=F(S, Z)$

DO $40 \mathrm{I}=1, \mathrm{~S}$

$Z(I)=\operatorname{CENTER}(I)-X I * \operatorname{HWIDTH}(I)$

SUM1 $=F(S, Z)$

$Z(I)=\operatorname{CENTER}(I)+\mathrm{X} I * \operatorname{HWIDTH}(I)$

SUM1 $=$ SUM1 $+F(S, Z)$

$Z(I)=\operatorname{CENTER}(I)-\mathrm{X} 2 * \operatorname{HWIDTH}(I)$

SUM2 $=F(S, Z)$

$\mathrm{Z}(\mathrm{I})=\operatorname{CENTER}(\mathrm{I})+\mathrm{X} 2 * \operatorname{HWIDTH}(\mathrm{I})$

SUM2 $=$ SUM2 $+F(S, Z)$

$Z(I)=\operatorname{CENTER}(I)$

$\mathrm{DIF}=\mathrm{ABS}(($ SUM1 - TWO $*$ SUMO $)-(\mathrm{X} 1 / \mathrm{X} 2) * 2 *($ SUM $2-$ TWO $*$ SUMO $))$

IF (DIF.LT.DIFMAX) GOTO 40

DIFMAX $=$ DIF

DIVAXN $=I$

40 CONTINUE

IF (SUMO.EQ.SUMO+DIFMAX/TWO) DIVAXN $=$ MOD (DIVAXO,S) +1

BASEST $=$ INTVLS (MINORD)

FUNCLS $=$ INTCLS $+4 * S$

RETURN 
END

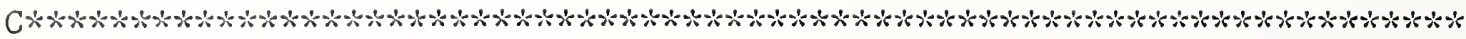
C

C

SUBROUTINE SYMRL(S, CENTER, HWIDTH, F, MINORD, MAXORD, INTVLS,

* INTCLS, NUMSMS, WEGHTS, FULSMS, FAIL)

IMPLICIT DOUBLE PRECISION (A-H,O-Z)

C MULTIDIMENSIONAL FULLY SYMMETRIC RULE INTEGRATION SUBROUTINE

C

C THIS SUBROUTINE COMPUTES A SEQUENCE OF FULLY SYMMETRIC RULE

C APPROXIMATIONS TO A FULLY SYMMETRIC MULTIPLE INTEGRAL.

C WRITTEN BY A. GENZ, MATHEMATICAL INSTITUTE, UNIVERSITY OF KENT,

C CANTERBURY, KENT CT2 7NF, ENGLAND

C

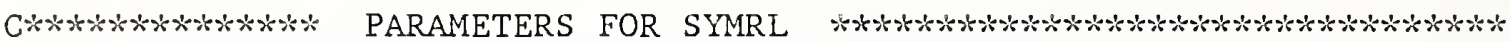
C $\div * * * \div \div$ INPUT PARAMETERS

$C$ INTEGER NUMBER OF VARIABLES, MUST EXCEED O BUT NOT EXCEED 20

C F EXTERNALLY DECLARED USER DEFINED REAL FUNCTION INTEGRAND.

C IT MUST HAVE PARAMETERS ( $S, X$ ), WHERE $X$ IS A REAL ARRAY

C WITH DIMENSION S.

C MINORD INTEGER MINIMUM ORDER PARAMETER. ON ENTRY MINORD SPECIFIES

$\mathrm{C}$

THE CURRENT HIGHEST ORDER APPROXIMATION TO THE INTEGRAL,

AVAILABLE IN THE ARRAY INTVLS. FOR THE FIRST CALL OF SYMRL MINORD SHOULD BE SET TO O. OTHERWISE A PREVIOUS CALL IS ASSUMED THAT COMPUTED INTVLS(1), .. , INTVLS(MINORD) . ON EXIT MINORD IS SET TO MAXORD.

MAXORD INTEGER MAXIMUM ORDER PARAMETER, MUST BE GREATER THAN MINORD AND NOT EXCEED 20. THE SUBROUTINE COMPUTES INTVLS(MINORD+1)。 INTVLS (MINORD+2) . . , INTVLS (MAXORD) .

G REAL ARRAY OF DIMENSION (MAXORD) OF GENERATORS. ALL GENERATORS MUST BE DISTINCT AND NONNEGATIVE.

NUMSMS INTEGER LENGTH OF ARRAY FULSMS, MUST BE AT LEAST THE SUM OF THE NUMBER OF DISTINCT PARTITIONS OF LENGTH AT MOST $S$ OF THE INTEGERS $0,1, \ldots$, MAXORD - 1 . AN UPPER BOUND FOR NUMSMS WHEN S+MAXORD IS LESS THAN 19 IS 200

C*******:OUTPUT PARAMETERS

$C$ INTVLS REAL ARRAY OF DIMENSION(MAXORD). UPON SUCCESSFUL EXIT

C

C

C

C INTCLS

C WEGHTS

C

C

C

C

C

C FAIL

C

C

C

C
INTVLS(1), INTVLS(2), .., INTVLS (MAXORD) ARE APPROXIMATIONS TO THE INTEGRAL. INTVLS $(D+1)$ WILL BE AN APPROXIMATION OF POLYNOMIAL DEGREE 2D+1. $S$ REAL WORKING STORAGE ARRAY WITH DIMENSION (NUMSMS). ON EXIT WEGHTS $(\mathrm{J})$ CONTAINS THE WEIGHT FOR FULSMS $(\mathrm{J})$.

FULSMS REAL WORKING STORAGE ARRAY WITH DIMENSION (NUMSMS). ON EXIT FULSMS(J) CONTAINS THE FULLY SYMMETRIC BASIC RULE SUM INDEXED BY THE JTH S-PARTITION OF THE INTEGERS $0,1, \ldots$, MAXORD -1 .

FAIL INTEGER FAILURE OUTPUT PARAMETER FAIL $=0$ FOR SUCCESSFUL TERMINATION OF THE SUBROUTINE FAIL $=1$ WHEN NUMSMS IS TOO SMALL FOR THE SUBROUTINE TO CONTINUE. IN THIS CASE WEGHTS(1), WEGHTS(2), ... WEGHTS (NUMSMS), FULSMS (1), $\operatorname{FULSMS~}(2), \ldots$, 
C

C

C

C

C

C*

EXTERNAL $F$

Cxix:- FOR DOUBLE PRECISION CHANGE REAL TO DOUBLE PRECISION

C IN THE NEXT STATEMENT

INTEGER D, I, FAIL, K(20), INTCLS, PRTCNT, L, M(20), MAXORD,

$*$ MINORD, MODOFM, NUMSMS, S, SUMCLS

DOUBLE PRECISION INTVLS, INTMPA, INTMPB

DOUBLE PRECISION MOMTOL, INTVAL, MOMENT, MOMPRD, MOMNKN

DIMENSION INTVLS (MAXORD), CENTER(S), HWIDTH(S)

DIMENSION FULSMS (NUMSMS), WEGHTS (NUMSMS)

DIMENSION MOMPRD $(20,20), \operatorname{MOMENT}(20), G(20)$

C PATTERSON GENERATORS

DATA G(1), G(2) /0.0000000000000000,0.7745966692414833/

DATA G(3), G(4) /0.9604912687080202,0.4342437493468025/

DATA G(5), G(6) /0.9938319632127549,0.8884592328722569/

DATA $G(7), G(8) / 0.6211029467372263,0.2233866864289668 /$

DATA $G(9), G(10), G(11), G(12) / 0.1,0.2,0.3,0.4 /$

C

C**** PARAMETER CHECKING AND INITIALISATION

FAIL $=2$

MAXRDM $=20$

MAXS $=20$

IF (S.GT.MAXS .OR. S.LT.1) RETURN

IF (MINORD.LT.O .OR. MINORD.GE.MAXORD) RETURN

IF (MAXORD.GT.MAXRDM) RETURN

ZERO $=0$

$\mathrm{ONE}=1$

TWO $=2$

MOMTOL $=$ ONE

10 MOMTOL $=$ MOMTOL/TWO

IF (MOMTOL+ONE.GT.ONE) GO TO 10

HUNDRD $=100$

MOMTOL $=$ HUNDRD $*$ TWO $*$ MOMTOL

$\mathrm{D}=$ MINORD

IF (D.EQ. O) INTCLS $=0$

C**-* CALCULATE MOMENTS AND MODIFIED MOMENTS

DO $20 \mathrm{~L}=1$, MAXORD

FLOATL $=\mathrm{L}+\mathrm{L}-1$

$\operatorname{MOMENT}(\mathrm{L})=$ TWO $/$ FLOATL

20 CONTINUE

IF (MAXORD.EQ.1) GO TO 50

DO $40 \mathrm{~L}=2$, MAXORD

INTMPA $=\operatorname{MOMENT}(\mathrm{L}-1)$

GLSQRD $=G(L-1) * * 2$

DO $30 \mathrm{I}=\mathrm{L}, \mathrm{MAXORD}$

INTMPB $=$ MOMENT $(I)$

$\operatorname{MOMENT}(\mathrm{I})=\operatorname{MOMENT}(\mathrm{I})-$ GLSQRD*INTMPA 


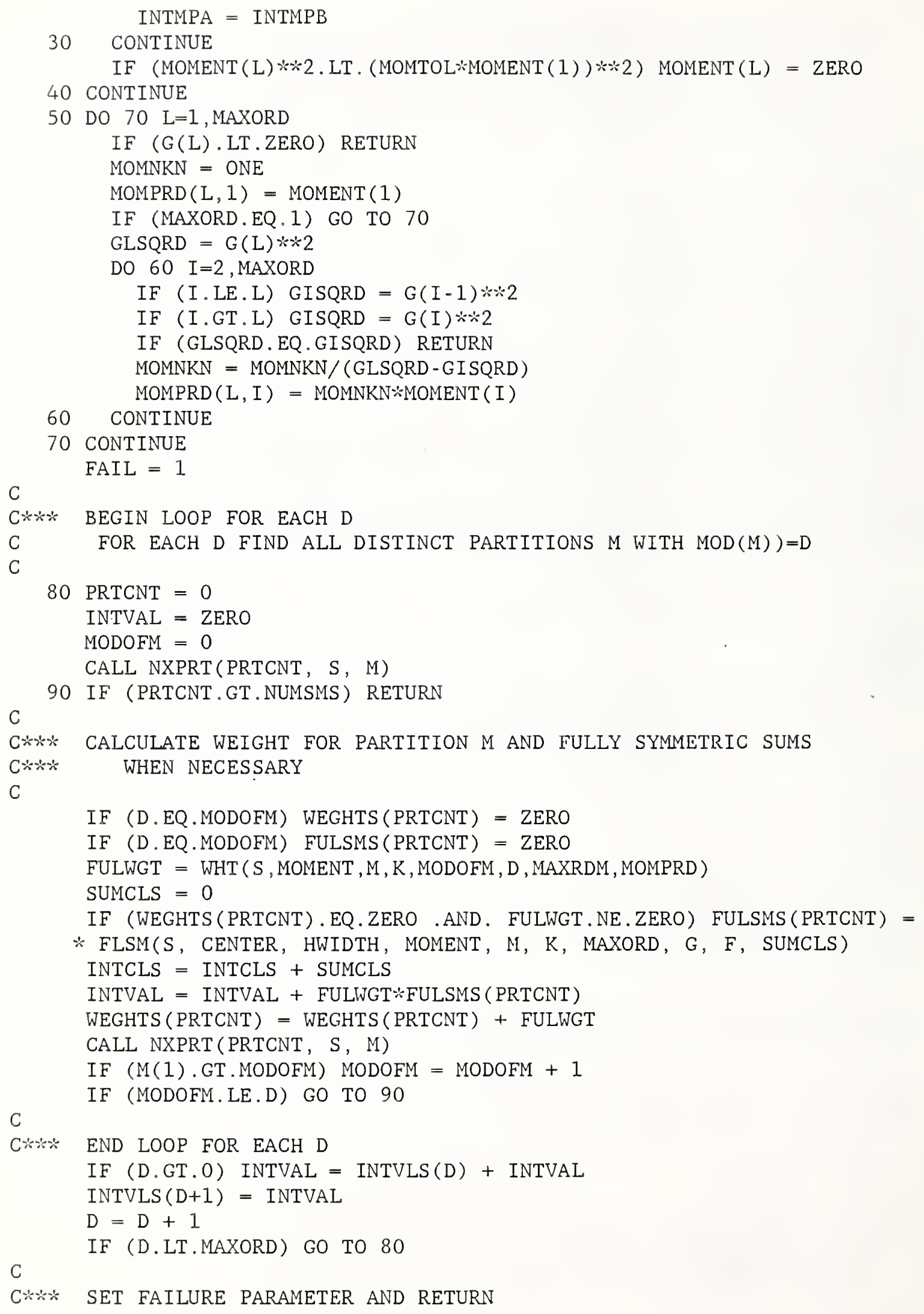




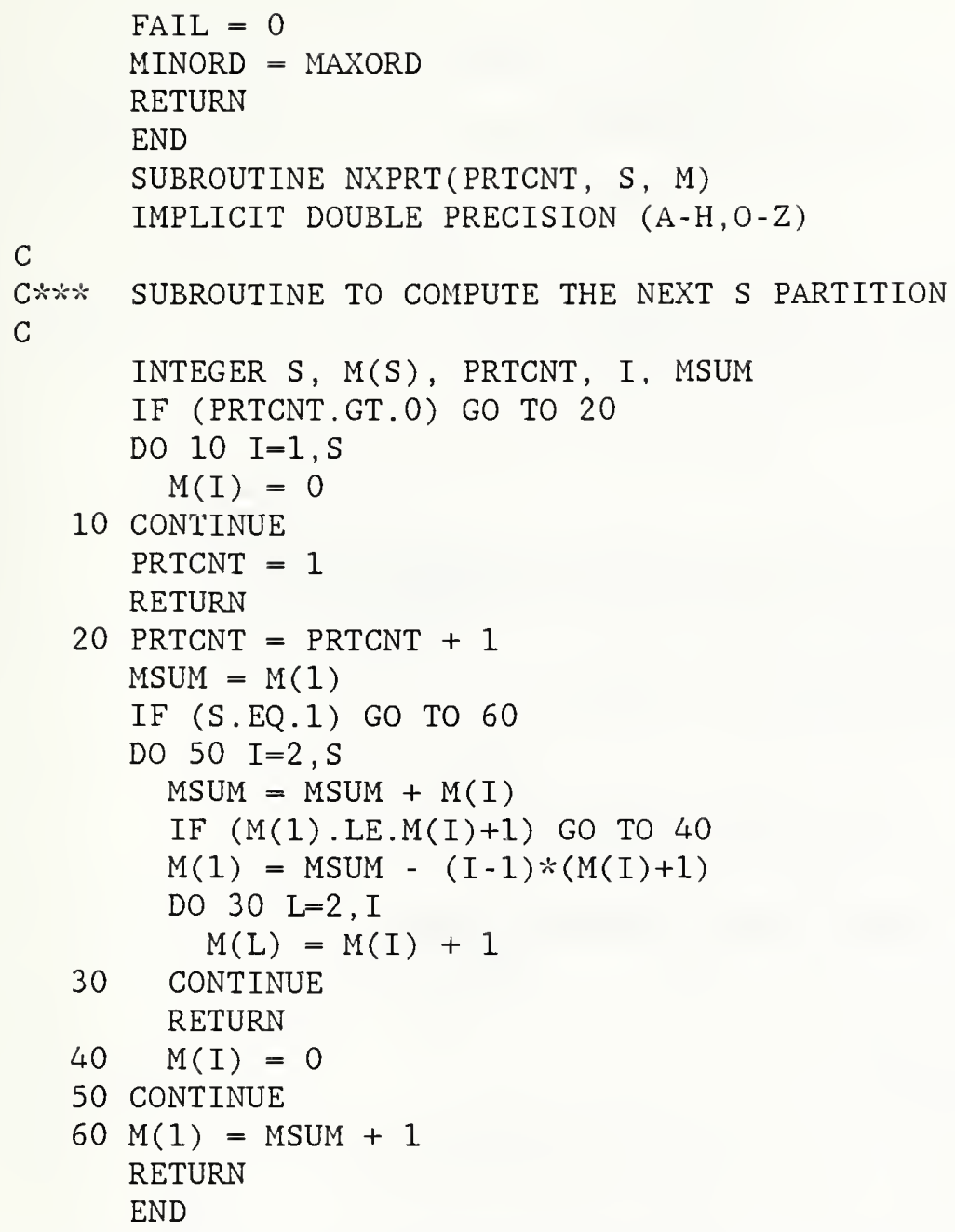

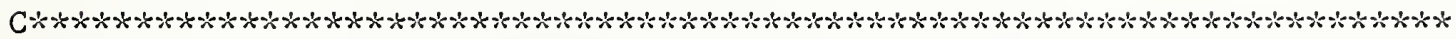
C C*x* DOUBLE PRECISION FUNCTION WHT

- (S, INTRPS, M, K, MODOFM, D, MAXRDM, MOMPRD) IMPLICIT DOUBLE PRECISION (A-H,O-Z)

C**** SUBROUTINE TO CALCULATE WEIGHT FOR PARTITION M

C

INTEGER $S, M(S), K(S), D$, MAXRDM, MI, KI, MI, K1, MODOFM DOUBLE PRECISION INTRPS, MOMPRD DIMENSION INTRPS (S), MOMPRD (MAXRDM, MAXRDM) ZERO $=0$ 
DO $30 \mathrm{I}=2, \mathrm{~S}$

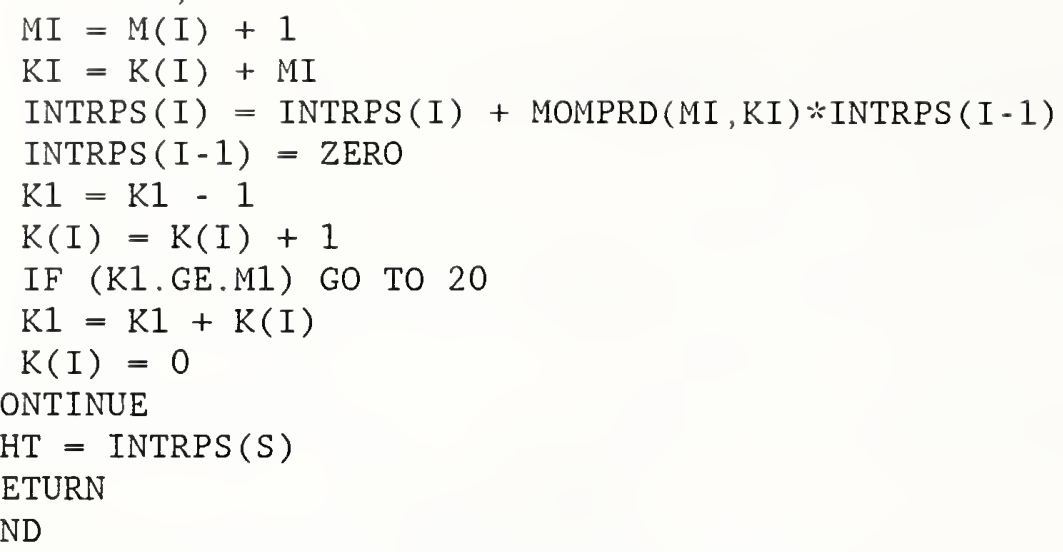

C

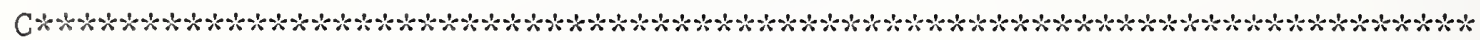
C*

DOUBLE PRECISION FUNCTION FLSM

( $S$, CENTER , HWIDTH , X, M , MP , MAXORD , G , F , SUMCLS )

IMPLICIT DOUBLE PRECISION (A-H,O-Z)

C EXTERNAL $F$

C*** FUNCTION TO COMPUTE FULLY SYMMETRIC BASIC RULE SUM

C

INTEGER $S, M(S), M P(S)$, MAXORD, SUMCLS, IXCHNG, LXCHNG, I, L, $*$ IHALF, MPI, MPL DOUBLE PRECISION INTWGT, INTSUM

DIMENSION G(MAXORD), $\mathrm{X}(\mathrm{S})$

DIMENSION CENTER(S), HWIDTH(S)

ZERO $=0$

$\mathrm{ONE}=1$

TWO $=2$

INTWGT $=$ ONE

DO $10 \mathrm{I}=1, \mathrm{~S}$

$M P(I)=M(I)$

IF (M(I).NE.O) INTWGT $=$ INTWGT $/$ TWO

INTWGT $=$ INTWGT $* \operatorname{HWIDTH}(\mathrm{I})$

10 CONTINUE

SUMCLS $=0$

FLSM $=$ ZERO

C

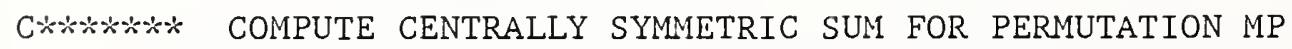

20 INTSUM $=$ ZERO

DO $30 \mathrm{I}=1, \mathrm{~S}$

$M P I=M P(I)+1$

30 CONTINUE

$\mathrm{X}(\mathrm{I})=\operatorname{CENTER}(\mathrm{I})+\mathrm{G}(\mathrm{MPI}) * \operatorname{HWIDTH}(\mathrm{I})$

40 SUMCLS $=$ SUMCLS +1

INTSUM $=$ INTSUM $+F(S, X)$

DO $50 \mathrm{I}=1, \mathrm{~S}$

$\mathrm{MPI}=\mathrm{MP}(\mathrm{I})+1$

$\operatorname{IF}(G(M P I) \cdot N E . Z E R O) \operatorname{HWIDTH}(I)=-\operatorname{HWIDTH}(I)$ 


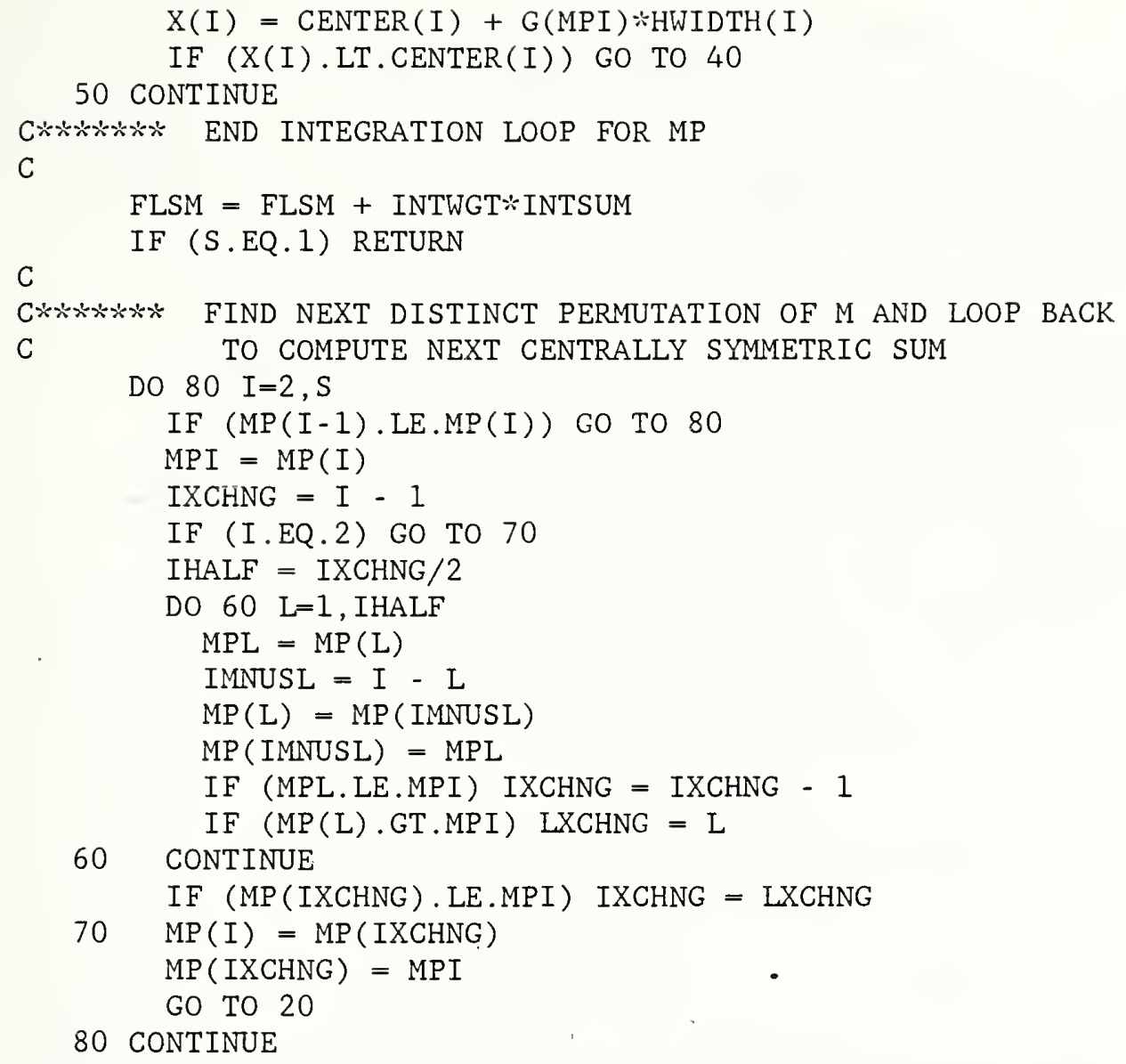




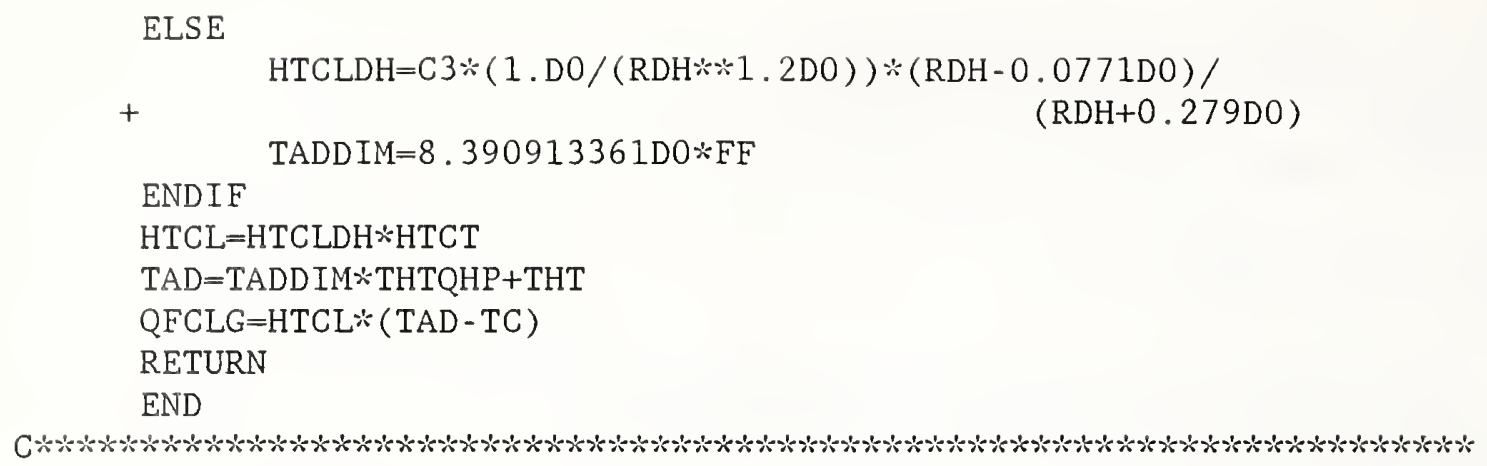



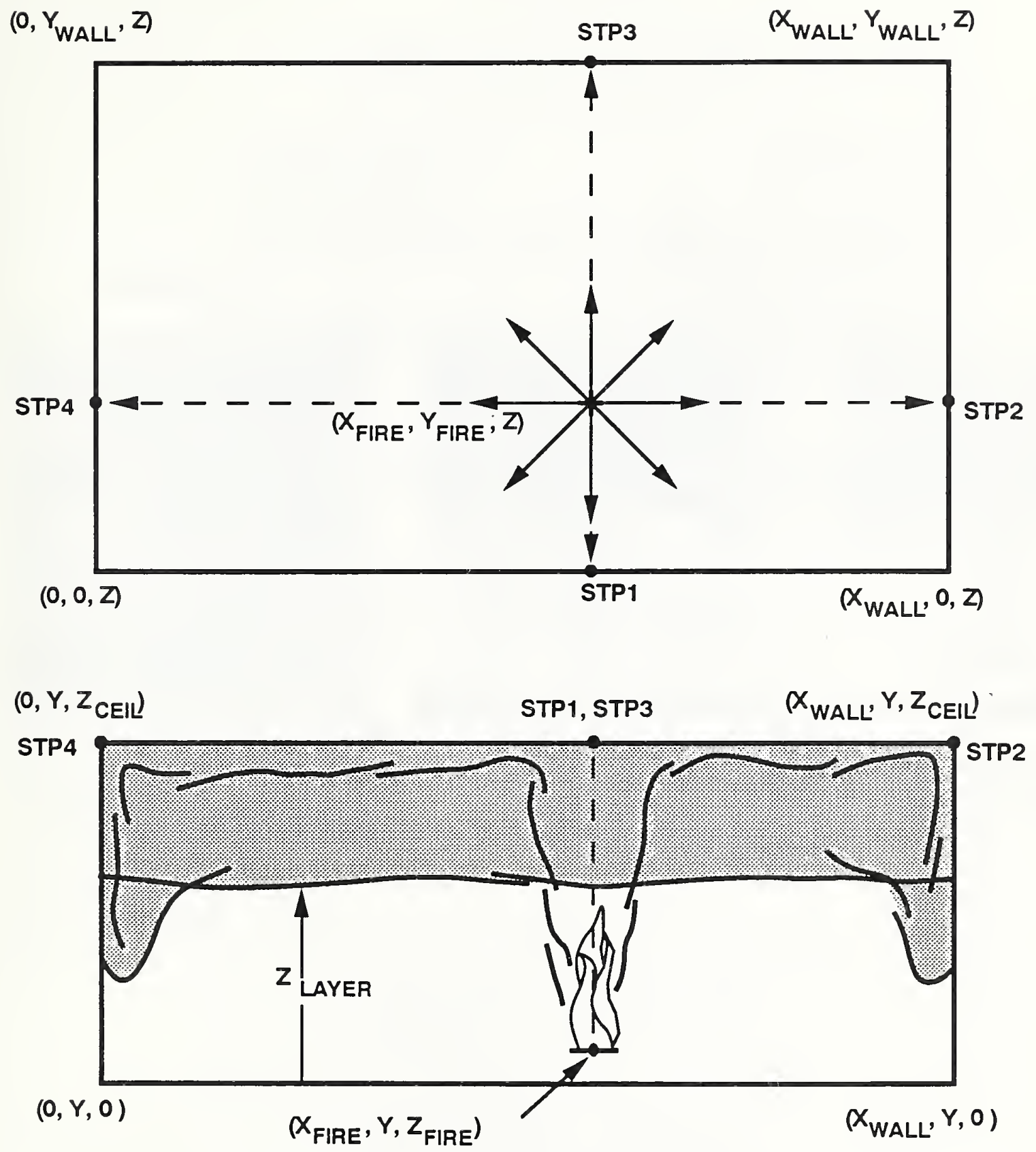

Figure 1. Fire in a rectangular parallelopiped enclosure. 


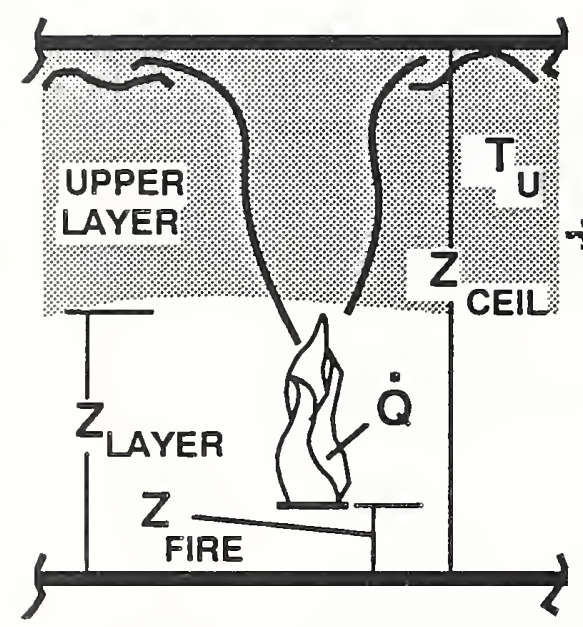

FIRE AND FLAMES IN THE LOWER LAYER

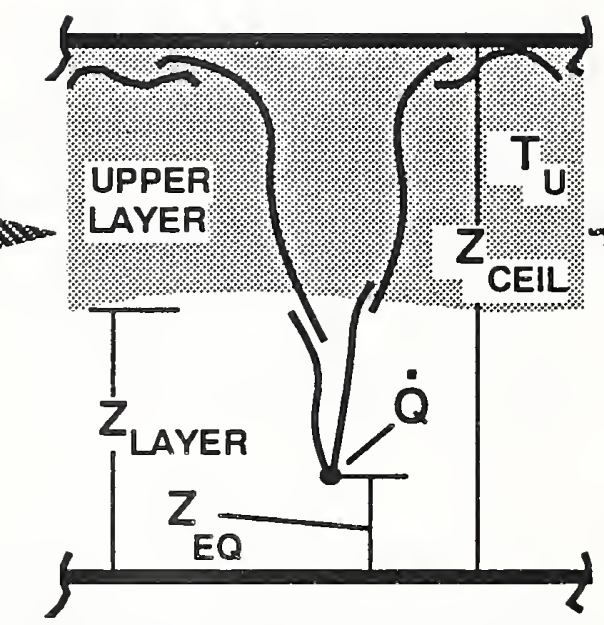

EQUIVALENT PLUME IN THE LOWER LAYER

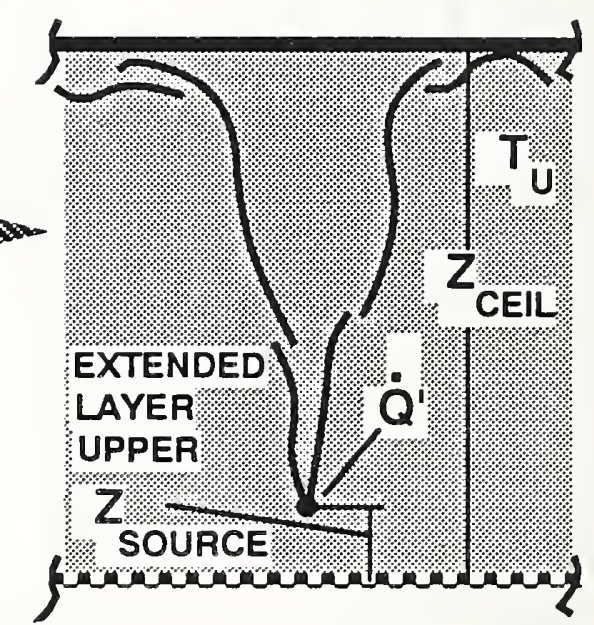

CONTINUATION PLUME IN THE EXTENDED UPPER LAYER

Figure 2. The fire and the equivalent source in the lower layer and the continuation source in the extended upper layer. 


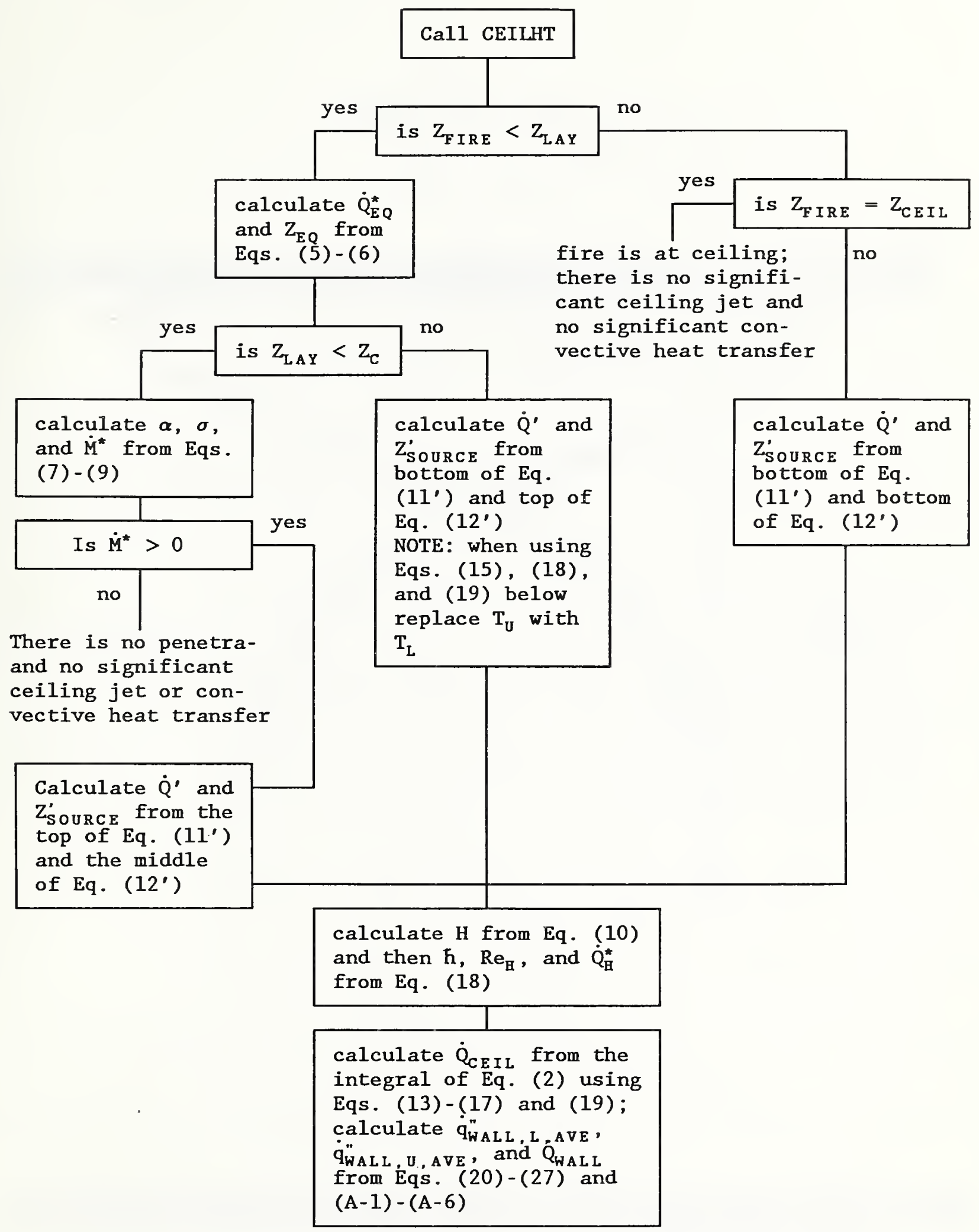

Figure 3. Overview of the CEILHT Algorithm. 


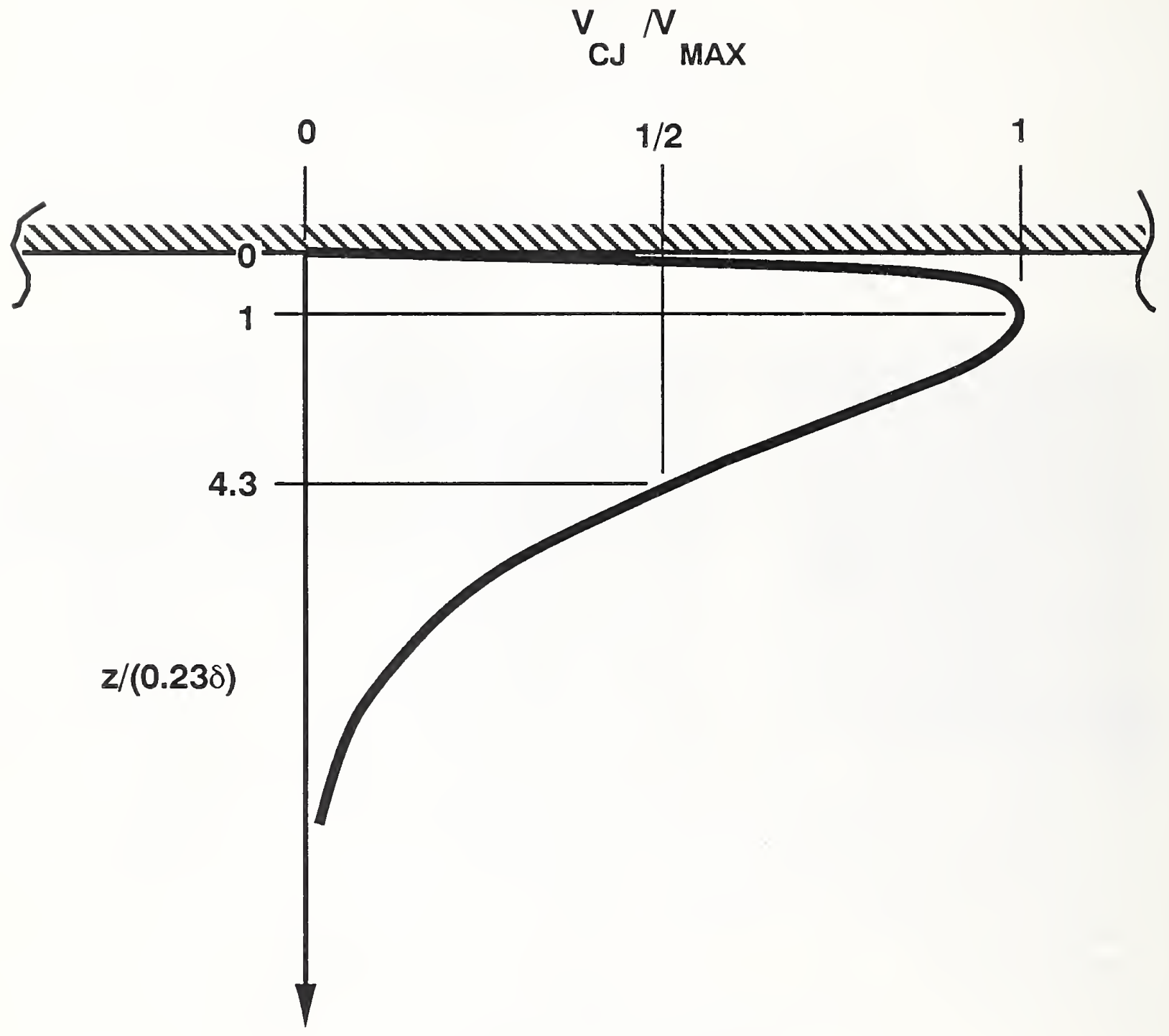

Figure 4. A plot of dimensionless ceiling jet velocity distribution, $\mathrm{V}_{\mathrm{CJ}} / \mathrm{V}_{\mathrm{MAX}}$, as a function of z/(0.23 $)$ per Eq. (29). 


$$
\Theta=\left(T_{C J}-T_{U}\right) /\left(T_{\text {MAX }}-T_{U}\right)
$$

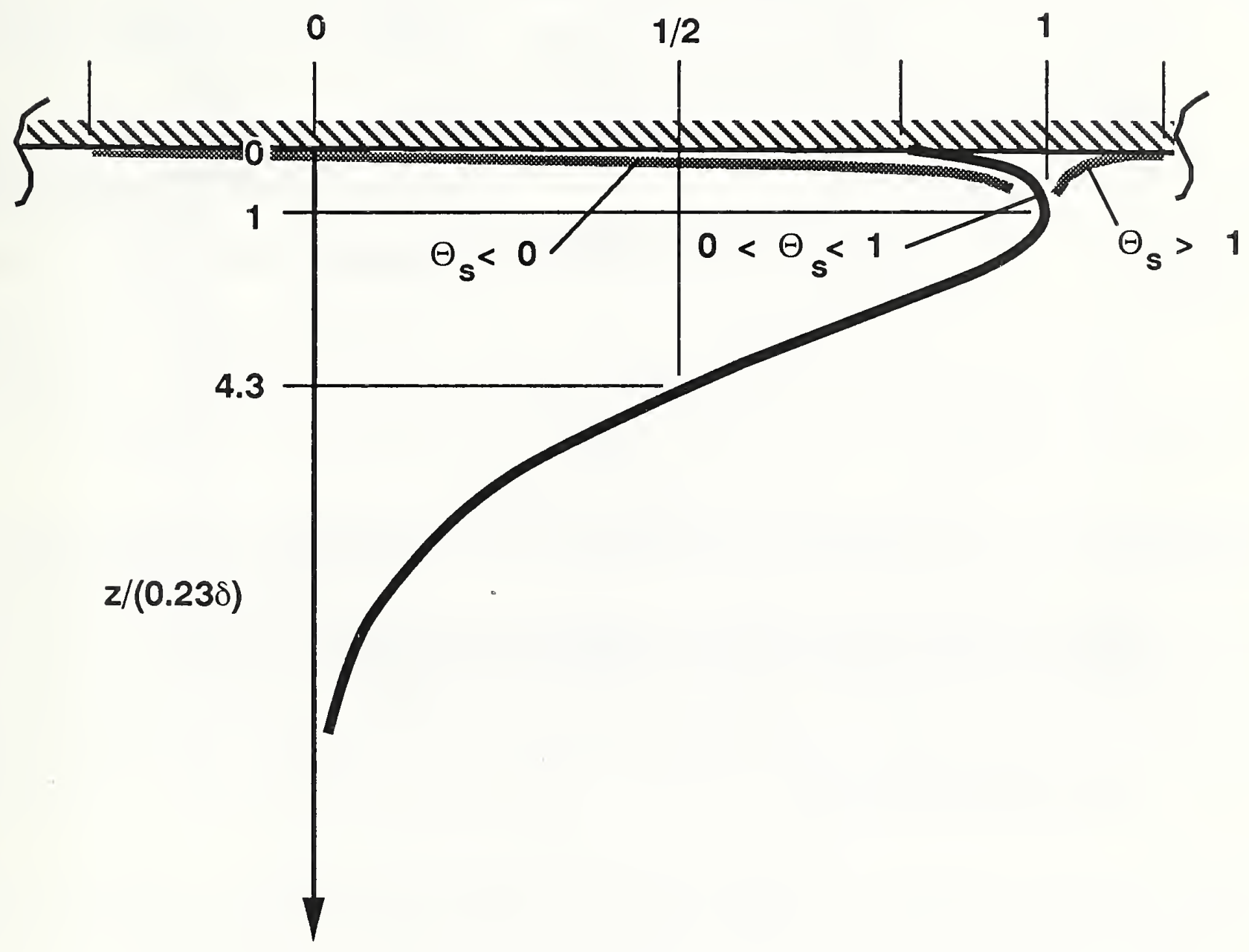

Figure 5. Plots of dimensionless ceiling jet temperature distribution, $\Theta$, as a function of $z /(0.23 \delta)$ per Eq. (32) for cases when $\Theta_{\mathrm{S}}$ is $<0$, between 0 and 1 , and $>0$. 


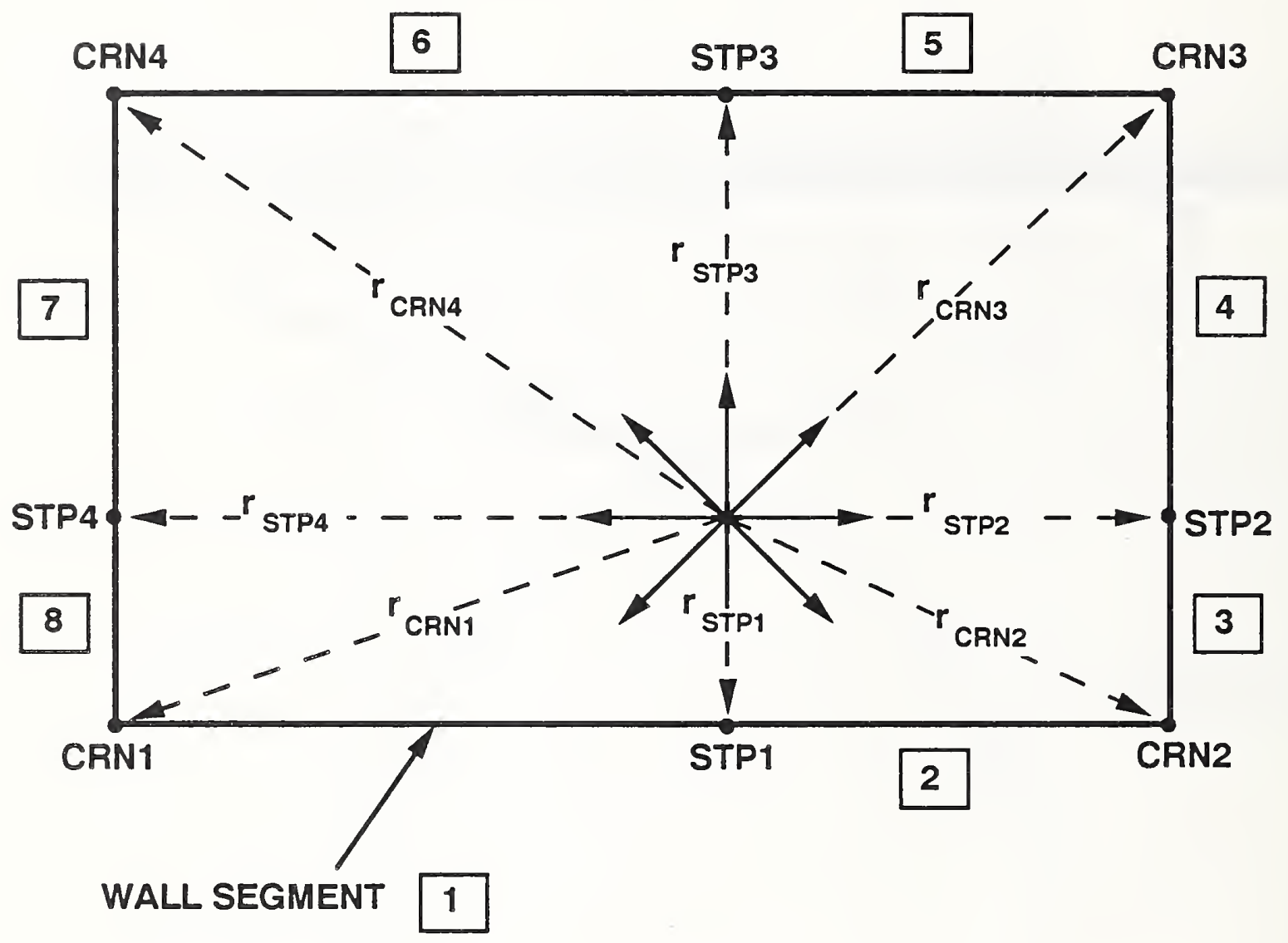

Figure 6. Definition of the Wall Stagnation Points, Room Corners, and Wall Segments. 
NIST-114A

(REV. 3-90)
U.S. DEPARTMENT OF COMMERCE NATIONAL INSTITUTE OF STANDARDS AND TECHNOLOGY

BIBLIOGRAPHIC DATA SHEET
1. PUBUCATION OR REPORT NUMEER

NISTIR 4705

2. PERFORMING ORGAMIZATION REPORT NUMBEF

3. PUBUCATION DATE

November 1991

4. TITLE AND SUBTITLE

FIRE-PLUME-GENERATED CEILING JET CHARACTERISTICS AND CONVECTIVE HEAT TRANSFER TO CEILING AND WALL SURFACES IN A TWO-LAYER ZONE-TYPE FIRE ENVIRONMENT: UNIFORM TEMPERATURE CEILING AND WALLS

5. AUTHOR(S)

\section{Lconard Y. Cooper}

\begin{tabular}{l|l|}
\hline 6. PERFORMINQ OROANIZATION (IF JOINT OR OTHER THAN NIST, SEE INSTRUCTIONS) & CONTRACT/GRANT NUMBER \\
U.S. DEPARTMENT OF COMMERCE \\
NATIONAL INSTITUTE OF STANDARDS AND TECHNOLOQY \\
GAITHERSBURG, MD 20899 & 8. TYPE OF REPORT AND PERIOD COVERED \\
\hline
\end{tabular}

9. SPONSORING ORGANIZATION NAME AND COMPLETE ADDRESS (STREET, CITY, STATE, ZIP)

\section{U.S. Nuclear Regulatory Commission}

Washington, DC 20555

10. SUPPLEMENTARY NOTES

11. AGSTRACT (A 200-WORD OR LESS FACTUAL SUMMARY OF MOST SIGNIFICANT INFOAMATION. IF DOCUMENT INCLUDES A SIGNIFICANT BIBLIOGRAPHY OR LTERATURE SURVEY, MENTION IT HERE.)

It has been determined by Sandia National Laboratories and the US Nuclear Regulatory Commission that the use of deterministic, multi-room, zone-type fïre modeling technology could enhance the reliability of their recent reactor salets risk studies. These studies are conlined to the relatively early detection times of fire development when fire-driven ceiling jets and gas-to-ceiling convective heat transier are expected to play a particularly important role in room-to-room smoke spread and in the response of near-ceiling mounted detection hardware. A parameter of concern in these risk analyses is the location of the lire within the space of fire origin. One goal of the analyses is to determine the significance to risk of this tire-position parameter.

This work presents a model to predict the instantaneous rate of convective heat transfer from fire plume gases to the overhead ceiling surface in a room of tire origin. The room is assumed to be a rectangular parallelopiped and, at times of interest. ceiling temperatures are simulated as being unitorm. Also presented is an estimate of the convective heat trans[er, due to ceiling-jet-driven wall tlows, to both the upper and lower portions of the walls. The elfect on the heal transfer of the location of the fire within the room is taken into account. Finally presented is a model of the velocit: and temperature distributions in the ceiling jet.

The model equations were used to develop an algorithm and associated modular computer subroutine to carry out the indicated heat transfer calculations, The subroutine is written in FORTRAN 77 and called CEILHT. The algorithm and subroutine are suitable for use in two-layer zone-type compartment fire model computer codes.

12. KEY WORDS (6 TO 12 ENTRIES; ALPHABETICAL ORDER; CAPITALZE ONLY PROPER NAMES; AND SEPARATE KEY WORDS BY SEMICOLONS)

building fires; ceiling jets; compartment Gires; computer models; fire models; heat transfer; mathematical models; zone models 
